\title{
Biomarkers allow detection of nutrient limitations and respective supplementation for elimination in Pichia pastoris fed-batch cultures
}

Jonas Burgard ${ }^{1,2}$, Minoska Valli ${ }^{1,2}$, Alexandra B. Graf ${ }^{2,3}$, Brigitte Gasser $^{1,2^{*}}$ (1) and Diethard Mattanovich ${ }^{1,2}$

\begin{abstract}
Background: Industrial processes for recombinant protein production challenge production hosts, such as the yeast Pichia pastoris, on multiple levels. During a common P. pastoris fed-batch process, cells experience strong adaptations to different metabolic states or suffer from environmental stresses due to high cell density cultivation. Additionally, recombinant protein production and nutrient limitations are challenging in these processes.

Results: Pichia pastoris producing porcine carboxypeptidase B (CpB) was cultivated in glucose or methanol-limited fed-batch mode, and the cellular response was analyzed using microarrays. Thereby, strong transcriptional regulations in transport-, regulatory- and metabolic processes connected to sulfur, phosphorus and nitrogen metabolism became obvious. The induction of these genes was observed in both glucose- and methanol- limited fed batch cultivations, but were stronger in the latter condition. As the transcriptional pattern was indicative for nutrient limitations, we performed fed-batch cultivations where we added the respective nutrients and compared them to non-supplemented cultures regarding cell growth, productivity and expression levels of selected biomarker genes. In the non-supplemented reference cultures we observed a strong increase in transcript levels of up to 89-fold for phosphorus limitation marker genes in the late fed-batch phase. Transcript levels of sulfur limitation marker genes were up to 35-fold increased. By addition of $\left(\mathrm{NH}_{4}\right)_{2} \mathrm{SO}_{4}$ or $\left(\mathrm{NH}_{4}\right)_{2} \mathrm{HPO}_{4}$, respectively, we were able to suppress the transcriptional response of the marker genes to levels initially observed at the start of the fed batch. Additionally, supplementation had also a positive impact on biomass generation and recombinant protein production. Supplementation with $\left(\mathrm{NH}_{4}\right)_{2} \mathrm{SO}_{4}$ led to $5 \%$ increase in biomass and $52 \%$ higher $\mathrm{CpB}$ activity in the supernatant, compared to the non-supplemented reference cultivations. In $\left(\mathrm{NH}_{4}\right)_{2} \mathrm{HPO}_{4}$ supplemented cultures $9 \%$ higher biomass concentrations and $60 \%$ more $\mathrm{CpB}$ activity were reached.
\end{abstract}

Conclusions: Transcriptional analysis of P. pastoris fed-batch cultivations led to the identification of nutrient limitations in the later phases, and respective biomarker genes for indication of limitations. Supplementation of the cultivation media with those nutrients eliminated the limitations on the transcriptional level, and was also shown to enhance productivity of a recombinant protein. The biomarker genes are versatily applicable to media and process optimization approaches, where tailor-made solutions are envisioned.

Keywords: Pichia pastoris, Yeast, Transcriptional regulation, Fed batch cultivation, Transcriptomics, Media optimization, Starvation, Nutrient limitation, Marker genes

\footnotetext{
*Correspondence: brigitte.gasser@boku.ac.at

2 Department of Biotechnology, BOKU-University of Natural Resources

and Life Sciences, Muthgasse 18, 1190 Vienna, Austria

Full list of author information is available at the end of the article
} 


\section{Background}

Production of heterologous proteins in yeast becomes more and more important in the biotechnological sector for research use, therapeutics or sustainable energy sources $[1,2]$. This development has led to the constant demand for improvement of hosts and processes for recombinant protein production (RPP). Common approaches for improvement of RPP are mostly based on strain engineering [3], process optimization [4] including adaptation of culture conditions [5-8], feed strategies [9], or media optimization [10, 11]. As production processes become more and more specific due to special needs of production hosts [11] and the recombinant product, media need to be developed for a specific process and are often tailor-made [12]. In general, cultivation media should be chemically defined, however, high level protein synthesis, influencing cell physiology, might make supplementation with e.g. amino acids necessary [13]. For bioreactor cultivations of the yeast production host Pichia pastoris (Komagataella spp.) different cultivation media have been developed. The original basal salt medium (BSM) [14] is a standard medium but comprises an unbalanced composition, tends to salt precipitation [15], and has a high ionic strength [12]. Adapted or alternative media have been tested by Zhang et al. [15], Kobayashi et al. [5], Zhao et al. [16], d'Anjou [17], Stratton et al. [18], or Maurer et al. [19] and also optimization approaches for $P$. pastoris biomass production have been published [20]. In this context challenges for media composition have been described. The modified basal salt medium (BSM) from Zhang et al. [15] e.g. might be problematic due to insufficient nutrient supply during growth upon precipitation of phosphorus compounds. Furthermore it has been reported that osmotic stress can lead to induction of the unfolded protein response [21] and high salinity may even inhibit growth or protein synthesis [22]. Such high salt concentrations can lead to loss of internal cellular pressure, effects on membrane transporter activity, ion homeostasis and internal $\mathrm{pH}$-equilibrium finally leading to protein misfolding and reactive oxygen species (ROS) generation [22]. Another problem might occur during downstream processing as high salt containing supernatants may need to be diluted to adapt conductivity for ion exchange chromatography [4].

Commonly performed industrial processes for production of recombinant proteins using a production host in a carbon-limited fed-batch can lead to starvation conditions at high biomass concentrations [11]. In this context it was already reported that downregulation of the protein synthesis machinery e.g. ribosome biogenesis [23, $24]$ and the secretion apparatus [25] occurred in starvation conditions in yeast processes, both having direct impact on product yield. The development of a cultivation medium can be achieved by e.g. determination of the elemental composition [26, 27] or an optimization by design of experiment (DoE)-approaches [28] which is more efficient than the traditional linear optimization process [29]. In such a setup, different supplements and concentrations can systematically be tested to find the optimum. The time required to customize a culture medium for a particular cell line depends on the goals [30].

Such studies indicate the need for tailor-made cultivation media for industrially relevant production strains and suitable methods to detect nutrient limitations. Studies on cellular adaptations upon starvation conditions have been already performed for model organisms e.g. Saccharomyces cerevisiae [31], but no data are available for cultivation of $P$. pastoris strains in a production process for recombinant proteins yet. Omics analyses so far have been used to understand the response of $P$. pastoris to different carbon sources [32,33], growth rates [34] and environmental conditions [35]. Furthermore it helped to understand the cellular reactions to recombinant protein production [36] and the results were used for strain engineering. Only the findings of Baumann et al. [8] were used for process design. As a complete characterization of the transcriptional regulatory patterns of a fed-batch process has not been performed so far, we set out to determine the gene expression levels of a strain cultivated either in a glucose or methanol-limited fed-batch, and use the regulatory insights to improve the production process.

\section{Results}

Methanol- and glucose-limited fed-batch cultivation of recombinant $P$. pastoris with equal biomass generation to allow comparable processes for transcriptomics analysis Pichia pastoris, producing porcine pro-carboxypeptidase $\mathrm{B}(\mathrm{CpB})$ under the control of the $\mathrm{P}_{\mathrm{GAP}}$-promoter was cultivated in standard methanol and glucose fed-batch processes (Fig. 1). In order to ensure comparability one strain that constitutively produces the recombinant product was chosen for both the glucose- as well as the methanol-based cultivations, and the processes were designed for equal biomass generation and feed volumes. The processes comprised a glycerol batch phase (IAM medium), followed by a limiting glycerol feed (GLY01 medium), subsequently the cultures were either pulsed with methanol for induction of the methanol metabolism or a low constant glucose feed of GLU04 medium was started. After consumption of the pulse, the methanol-grown cultures received a constant methanol feed (MET01 medium), while the glucose-grown cultures received a constant glucose feed for $67 \mathrm{~h}$. These media, 


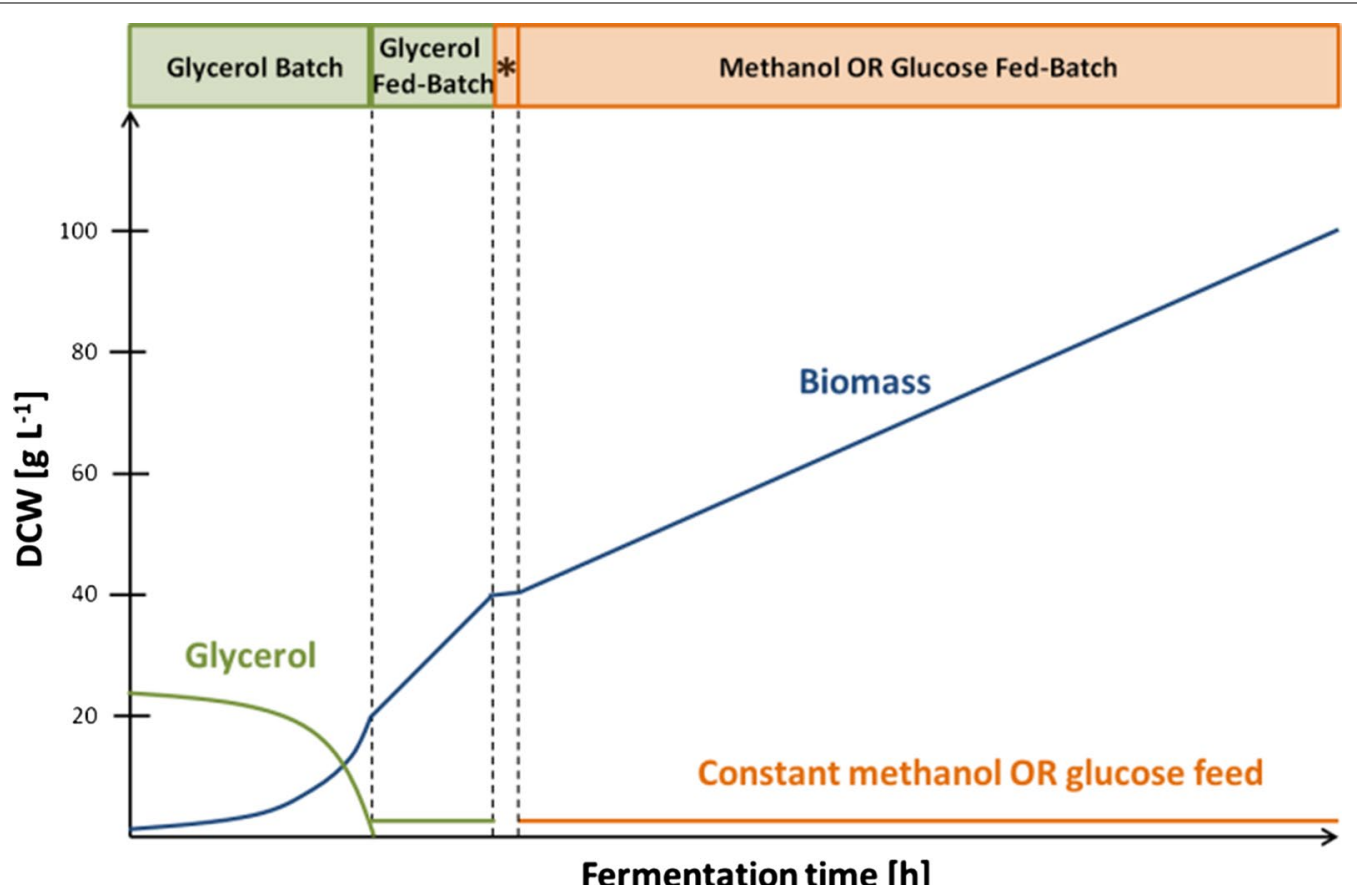

Fig. 1 Schematic representation of the fed-batch cultivations for transcriptional analysis of $P$. pastoris. The process comprised a glycerol batch phase, followed by a limiting glycerol fed-batch for $5 \mathrm{~h}$ to double the biomass. Then methanol-grown cultures received a methanol pulse, while glucose-grown cultures were slowly fed with glucose to accumulate the same amount of biomass during this period (Asterisk). Afterwards a constant methanol or glucose feed was applied

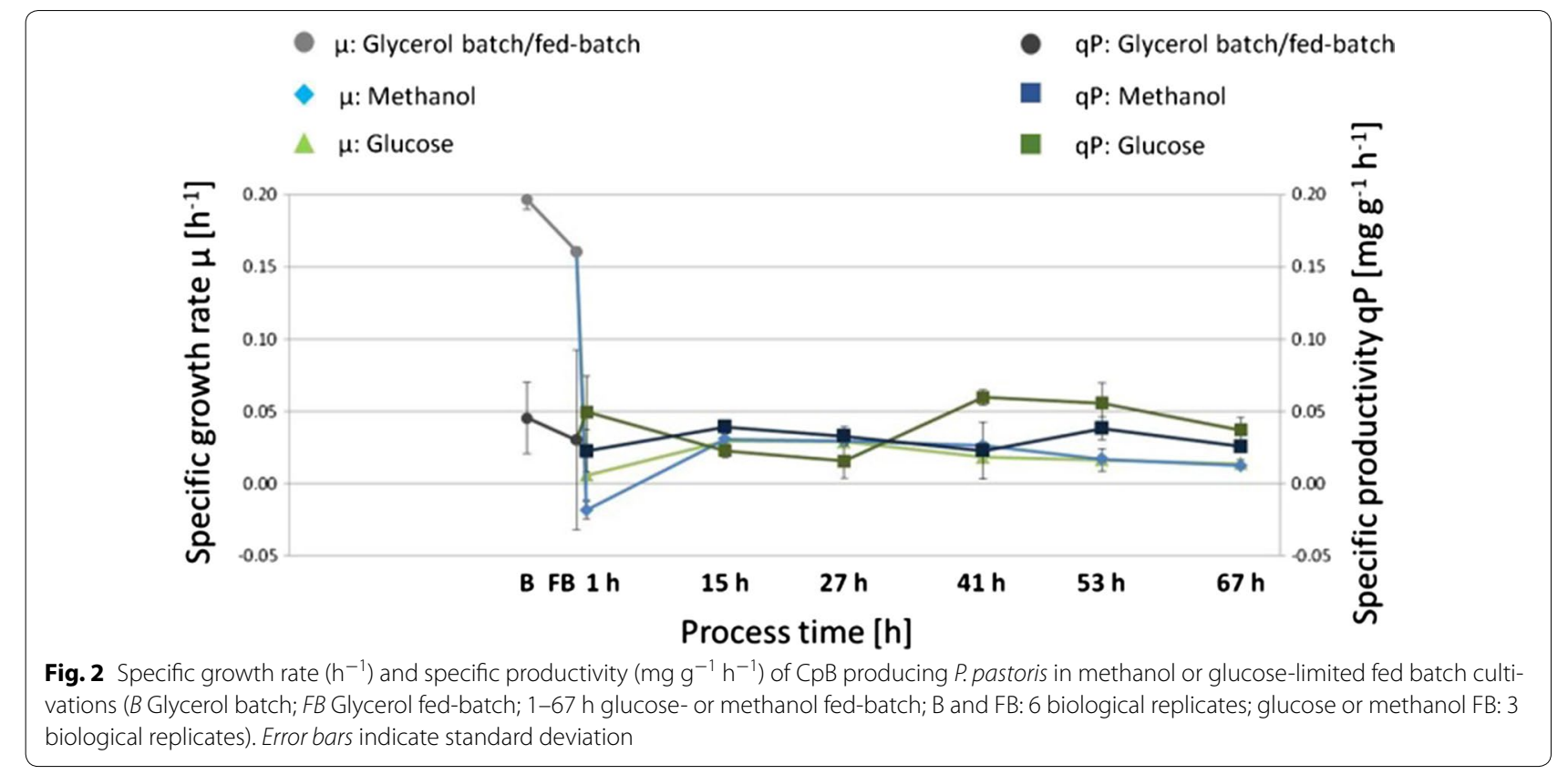

described in detail in the "Methods" section, were successfully used for several recombinant protein production processes before. Both processes were performed in triplicates. Samples were taken in regular intervals and characterized for growth and $\mathrm{CpB}$ production. Furthermore, transcriptome analyses were performed to study the cellular response over the course of the production processes. 
The biomass (dry cell weight; DCW) reached 21 $( \pm 1) \mathrm{g} \mathrm{L}^{-1}$ after the glycerol batch and $44( \pm 2) \mathrm{g} \mathrm{L}^{-1}$ after glycerol fed-batch. After $67 \mathrm{~h}$, methanol-grown cultures reached $103( \pm 5) \mathrm{g} \mathrm{L}^{-1} \mathrm{DCW}$ and glucose-grown cultures $103( \pm 3) \mathrm{g} \mathrm{L}^{-1} \mathrm{DCW}$. The culture viability remained high throughout the glucose and methanol-based processes $(>96 \%)$. During the process, the specific growth rate decreased from 0.2 to $0.01 \mathrm{~h}^{-1}$ upon the increasing carbon limitation (Fig. 2). Specific productivity differed during the adaptation phase for methanol metabolism and the very low glucose feed. For the methanol-limited fed batch it stayed stable at about $0.03 \mathrm{mg} \mathrm{g}^{-1} \mathrm{~h}^{-1}$, whereas for the glucose-limited processes it was higher in the second half of the feed phase, compared to the first phase.

Strong transcriptional response upon change of carbon source and increase in gene regulation in high cell density cultures is occurring in $P$. pastoris fed batch cultivations

Pichia pastoris specific microarray analyses were performed of samples from the end of the glycerol batch, the end of glycerol fed-batch and from methanol or glucose fed-batches $(1,15,27,41,53$ and $67 \mathrm{~h}$ after starting the constant feed) and expression patterns were investigated. Differentially regulated genes $\left(\log _{2} \mathrm{FC} \leq-0.58\right.$ $\mathrm{OR} \geq 0.58$; AND adjusted $\mathrm{P}$ value $<0.05$ ) were determined taking the end of the glycerol fed-batch phase, as last common condition, as reference. The numbers of differentially regulated genes are shown in Fig. 3. In the methanol fed-batch we observed a strong induction of gene regulation (significant up- and downregulation) $1 \mathrm{~h}$ after starting the methanol feed $(50 \%)$ correlating to restructuring of metabolism towards methanol utilization. This is in contrast to the early phase of the glucose fed-batch where we observed a lower degree of gene regulation (17\%). After the early adaptation phase both processes show the same trend for increased gene regulation from the middle (25\%) to the end of the fed-batch processes ( $35 \%)$. The proportion of up- and downregulated genes is very similar and follows the same trend during the fed-batch process on both carbon sources. A probe for the $\mathrm{CpB}$ gene was also included on the microarrays and expression remained constantly high throughout the cultivation, both on methanol and glucose as carbon source (Additional file 1: Figure S1).

For all comparisons, GO term analysis was performed to identify overrepresented functional categories (Fig. 4), while principal component analysis (PCA) revealed similarities between the different analysed time points (Fig. 5).

For generation of a compact overview of the transcriptional response to the carbon limited fed-batch conditions at high cell densities (up to $100 \mathrm{~g} \mathrm{~L}^{-1} \mathrm{DCW}$ ), we grouped significantly regulated genes in the middle $(27 \mathrm{~h})$ and the end of the methanol and glucose fed-batch $(67 \mathrm{~h})$ for their cellular functions using GO-slim terms (http:// www.yeastgenome.org/help/analyze/go-slim-mapper) (Fig. 4). This excerpt of the fed-batch process is shown

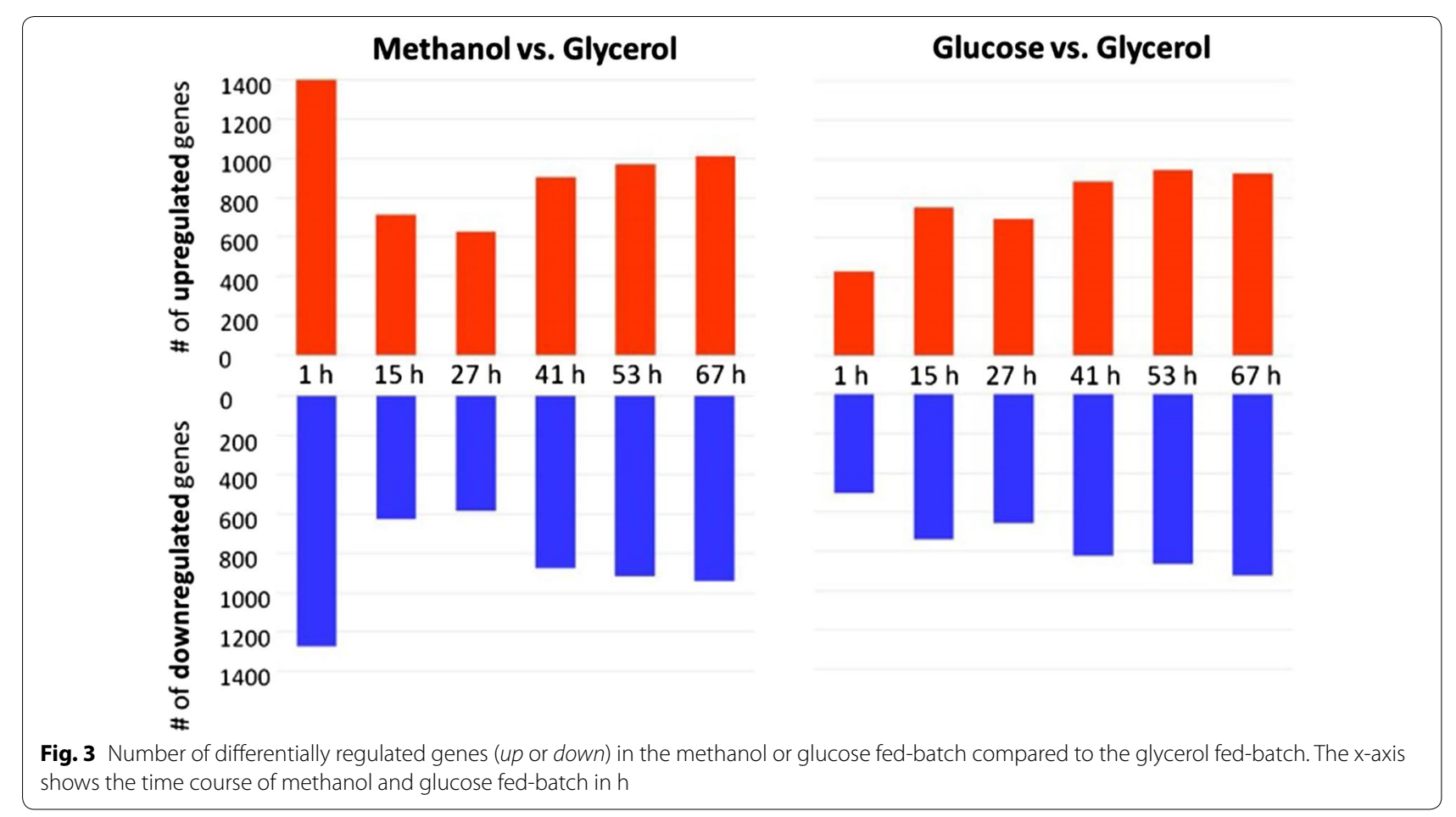




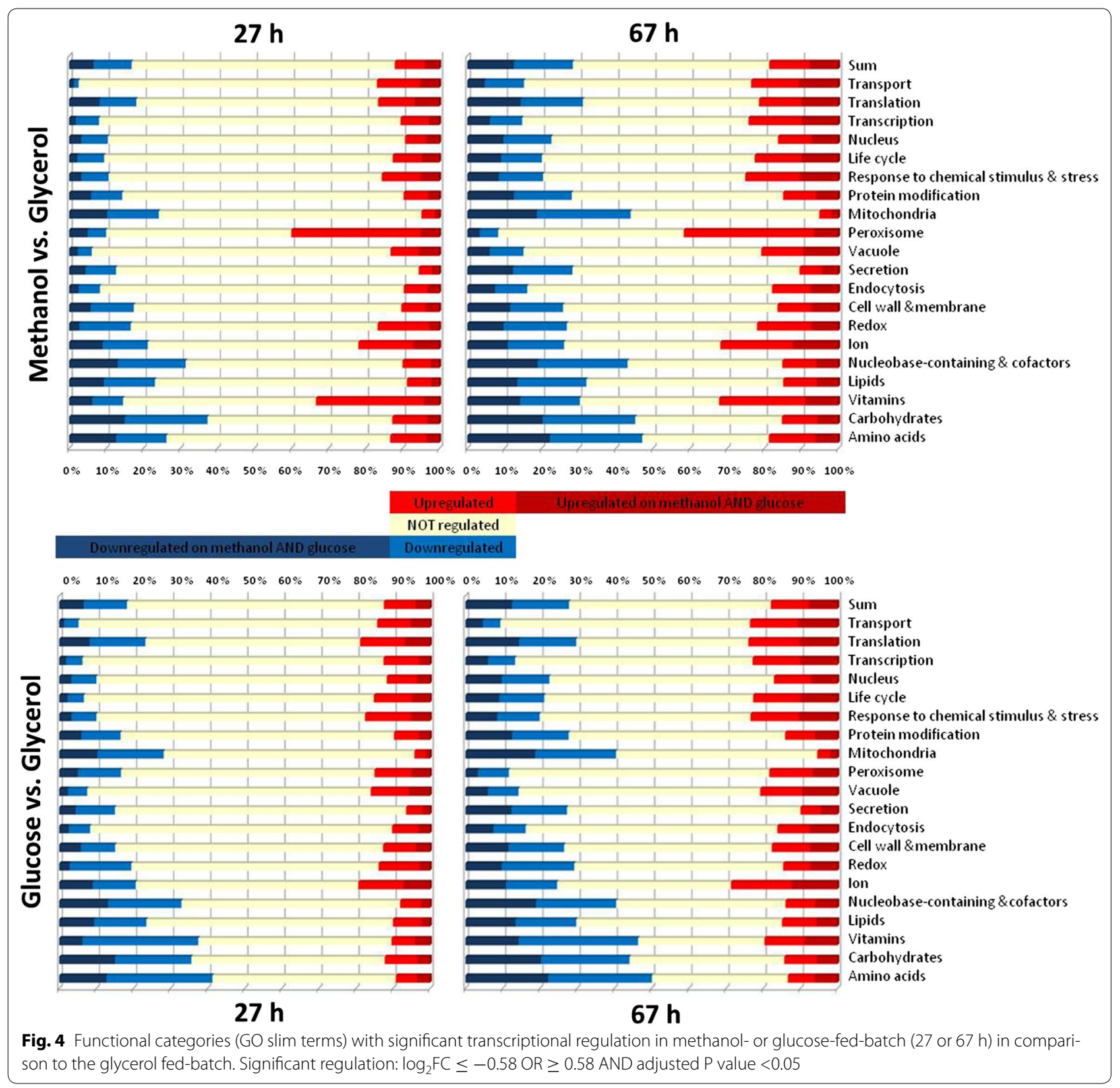

exemplarily as the methanol and glucose fed-batch can be divided by their transcriptional response in an early $(1 \mathrm{~h})$, middle $(15,27 \mathrm{~h})$ and late fed-batch phase $(41,53,67 \mathrm{~h})$ using PCA; (Fig. 5 and Additional file 1: Figures S4-S7).

Analyzing the time course of the methanol or glucose fed-batch (27 and $67 \mathrm{~h})$ those graphs show an increasing number of downregulated genes associated with translation, correlating with the decreasing carbon source availability and specific growth rate. Furthermore an increasing regulation in cell cycle genes, the downregulation of energy metabolism (mitochondria) and of pathways associated with nucleobases and cofactors, lipids, carbohydrates and amino acids was observed in both conditions over the time course. The strongest differences between methanol and glucose grown cells were in the upregulation of peroxisomal genes and vitamins (see Russmayer et al. [33]) which were strongly upregulated during the methanol fed-batch. Interestingly also many transport pathways (endocytosis, ions) and pathways, including metabolic recycling for providing alternative substrates (e.g. amino acids) by the vacuole as replacement for preferred substrates were strongly 

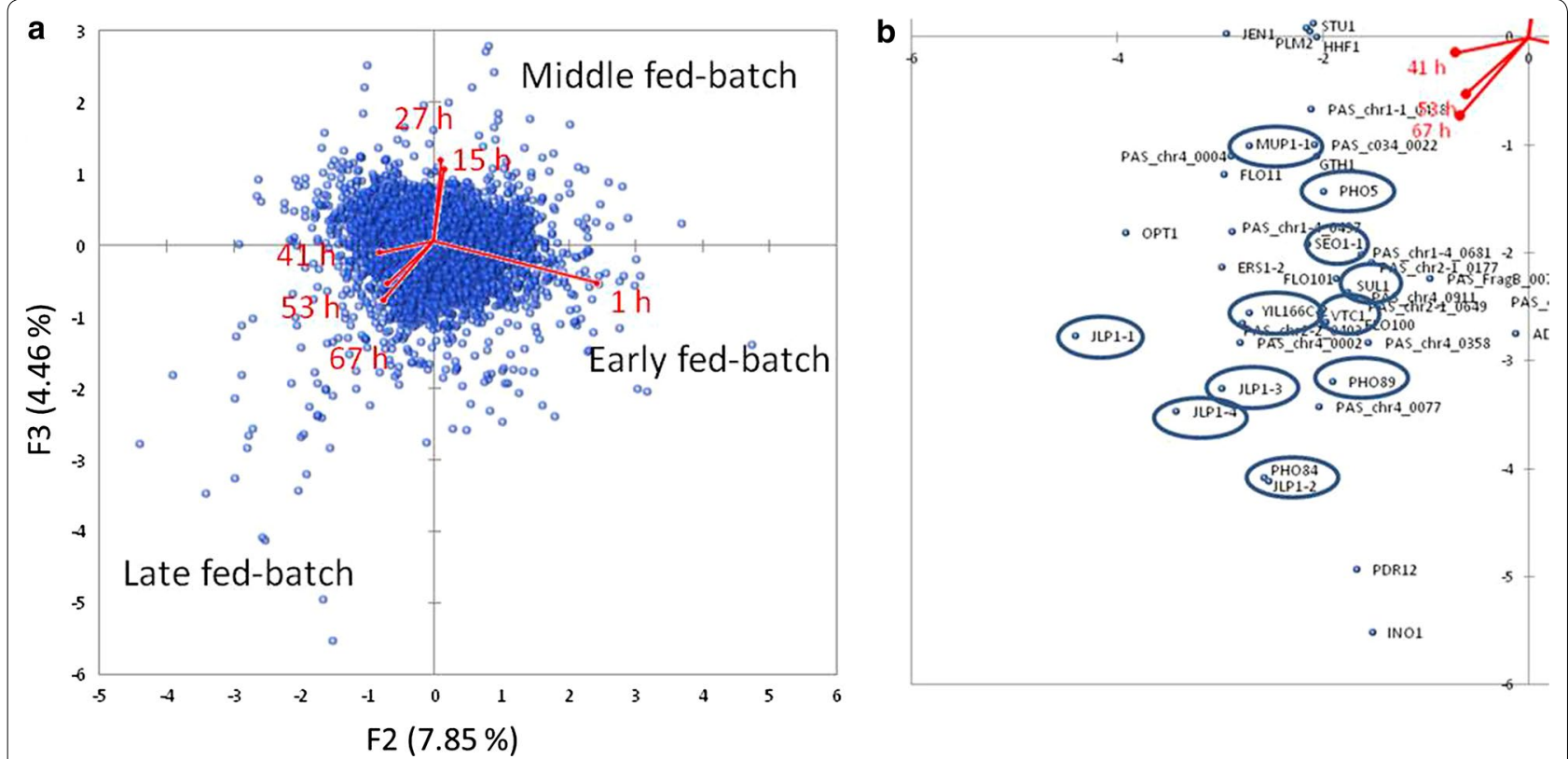

Fig. 5 Principal component analysis (PCA) bi-plots of the methanol fed-batch $(1,15,27,41,53$ and $67 \mathrm{~h}$ after starting the methanol fed-batch) referred to the glycerol fed-batch ( $\log _{2}$ fold change). a Vectors indicate variables (sampling time points) and blue data points indicate individuals (genes). b Excerpt from quadrant 4 with genes that were strongly regulated in the later fed-batch phase (reduced for individuals with variance below 2\%). Genes involved in metabolism of nitrogen, phosphorus and sulfur are highlighted by circles

transcriptionally regulated. This number even increased from the middle $(27 \mathrm{~h})$ to the later fed-batch $(67 \mathrm{~h})$ and was more pronounced in the methanol fed-batch, compared to the glucose fed-batch.

\section{Transcriptome data reveal limitations of the macroelements sulfur, phosphorus and nitrogen}

For further investigation of the changes in gene regulation being representative for the late phases of the fedbatch processes $(41,53$, and $67 \mathrm{~h})$, we inspected quadrant 4 of the PCA plot (Fig. 5b). In this analysis we identified many genes associated with sulfur, phosphorus and nitrogen metabolism indicating for nutrient limitations. Genes involved in sulfur metabolism, include $J L P 1-1$, JLP1-2, JLP1-3, SUL1, YIL166C2, and MUP1-1. Phosphorus-associated genes were PHO5, PHO84, PHO89, and $V T C 1$. Nitrogen-associated genes were e.g. DUR3-1, SEO1, and $Y B R 139 W$.

For further investigation of the transcriptomics data we focused on those genes and made a selection of genes involved in metabolism, regulatory and transport processes. Transcriptomics data of all genes associated with limitations of these nutrients are shown in $\log _{2}$ fold changes in the heat maps in Fig. 6 (description of biological function in Additional file 1: Table S2).

Transcriptional regulation of these genes, compared to the glycerol fed-batch, mostly followed a similar trend in the methanol fed-batch since expression levels were strongly induced upon the change of the carbon source $(1 \mathrm{~h})$, then they decreased to a not or only slightly differentially regulated state, and later on strongly increased from the middle to the end of the fed-batch (41-67 h). The highest changes were observed for the phosphate transporter $\mathrm{PHO} 84$ with a $\log _{2} \mathrm{FC}$ of 4.55 corresponding to a 23-fold upregulation. Summarizing the functional distribution, mainly gene products involved in nutrient uptake, metabolism of alternative/non-preferred sources of the respective nutrients and correlating upregulation of the respective pathways were found. As already described for the overall transcriptional regulation in the glucose fed-batch, there is just a weak induction of gene regulation upon the change of carbon source. During the late fed-batch, increasing upregulation of potential marker genes for sulfur-limitation was less pronounced whereas induction of the selected phosphorus-associated genes was comparable to the observed level of upregulation during the methanol fed-batch. And also nitrogen associated genes followed the same trend, albeit having a weaker induction.

Based on PCA analyses and the pronounced regulatory trend of gene regulation displayed in the heat maps, nutrient limitations can be assumed. Therefore, we analyzed and compared the media composition of our medium with different published cultivation media. 


\begin{tabular}{|c|c|c|c|c|c|c|c|c|c|c|c|c|c|c|c|}
\hline \multirow{9}{*}{$\begin{array}{l}\text { 는 } \\
\text { 음 } \\
\text { 음 } \\
\frac{0}{2}\end{array}$} & & \multicolumn{6}{|c|}{ Methanol fed-batch compared to glycerol fed-batch } & \multicolumn{8}{|c|}{ Glucose fed-batch compared to glycerol fed-batch } \\
\hline & & $1 \mathrm{~h}$ & $15 \mathrm{~h}$ & $27 \mathrm{~h}$ & $41 \mathrm{~h}$ & $53 \mathrm{~h}$ & $67 \mathrm{~h}$ & \multirow{31}{*}{$-\quad+$} & $1 \mathrm{~h}$ & $15 \mathrm{~h}$ & $27 \mathrm{~h}$ & $41 \mathrm{~h}$ & $53 \mathrm{~h}$ & $67 \mathrm{~h}$ & \multirow{8}{*}{$\begin{array}{l}\text { Category } \\
\text { transport } \\
\text { transport } \\
\text { transport } \\
\text { regulation } \\
\text { regulation } \\
\text { metabolism } \\
\text { metabolism }\end{array}$} \\
\hline & PHO84 & 0.98 & 0.08 & 0.10 & 1.87 & 3.54 & 4.55 & & 0.22 & -0.26 & -0.43 & 2.95 & 4.29 & 4.99 & \\
\hline & PHO89 & 1.15 & 0.41 & 0.25 & 1.49 & 2.87 & 4.08 & & 0.27 & 0.31 & 0.99 & 2.41 & 3.63 & 4. 19 & \\
\hline & VTC1 & -0.09 & -0.18 & -0.22 & 0.85 & 1.89 & 2.86 & & -0.07 & -0.52 & -0.39 & 1.12 & 2.04 & 2.65 & \\
\hline & PHO8O & 0.34 & 0.10 & 0.20 & 0.18 & 0.50 & 0.81 & & -0.02 & 0.21 & 0.23 & 0.62 & 0.93 & 1.33 & \\
\hline & PHO81 & 1.09 & 0.31 & 0.03 & 0.67 & 1.27 & 1.71 & & 0.44 & 0.25 & 0.06 & 1.09 & 1.69 & 2.12 & \\
\hline & \multirow{2}{*}{ PHO5 } & -0.07 & -0.06 & -0.25 & 0.13 & 0.35 & 0.77 & & -0.76 & -0.03 & -0.16 & -0.02 & 0.37 & 1.14 & \\
\hline & & -0.57 & 0.32 & 0.34 & 0.58 & 1.17 & 3.05 & & -0.52 & -0.20 & -0.23 & 0.45 & 1.82 & 3.32 & \\
\hline \multirow{14}{*}{ 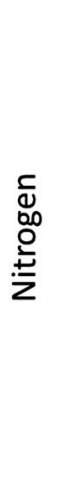 } & & $1 \mathrm{~h}$ & $15 \mathrm{~h}$ & $27 \mathrm{~h}$ & $41 \mathrm{~h}$ & $53 \mathrm{~h}$ & $67 \mathrm{~h}$ & & $1 \mathrm{~h}$ & $15 \mathrm{~h}$ & $27 \mathrm{~h}$ & $41 \mathrm{~h}$ & $53 \mathrm{~h}$ & $67 \mathrm{~h}$ & \multirow{13}{*}{$\begin{array}{l}\text { Category } \\
\text { transport } \\
\text { transport } \\
\text { transport } \\
\text { transport } \\
\text { transport } \\
\text { transport } \\
\text { metabolism } \\
\text { metabolism } \\
\text { metabolism } \\
\text { metabolism } \\
\text { regulation } \\
\text { other }\end{array}$} \\
\hline & DAL4 & 0.21 & 0.24 & 0.28 & 0.39 & 0.49 & 0.62 & & 0.75 & 0.50 & 0.54 & 0.61 & 0.71 & 0.61 & \\
\hline & DAL5-2 & 0.15 & 0.62 & 0.50 & 0.48 & 0.53 & 0.65 & & 0.29 & 0.59 & 0.27 & 0.39 & 0.46 & 0.26 & \\
\hline & DUR3-1 & 4.83 & 1.53 & 1.18 & 1.32 & 1.66 & 1.99 & & 1.22 & 1.05 & 1.02 & 1.54 & 1.80 & 1.66 & \\
\hline & DUR3-2 & 1.47 & 0.21 & 0.40 & 0.42 & 0.58 & 0.66 & & 0.17 & -0.06 & 0.09 & 0.57 & 0.67 & 0.38 & \\
\hline & TPO2 & 3.90 & 2.15 & 2.31 & 3.41 & 3.86 & 4.25 & & 0.96 & 1.13 & 1.54 & 2.27 & 2.55 & 3.02 & \\
\hline & SEO1-1 & 1.24 & 0.78 & 1.16 & 3.18 & 3.14 & 3.15 & & 0.71 & 1.27 & 1.05 & 1.07 & 1.08 & 1.03 & \\
\hline & PUT1 & 2.38 & 1.00 & 0.79 & 1.31 & 1.62 & 2.23 & & 0.74 & 1.14 & 1.04 & 1.24 & 1.71 & 2.72 & \\
\hline & CAR1-1 & 2.88 & 0.75 & 0.62 & 1.51 & 2.00 & 2.24 & & 1.19 & 1.65 & 1.88 & 1.47 & 1.27 & 1.07 & \\
\hline & GLT1 & 2.83 & 1.27 & 1.27 & 0.80 & 1.20 & 1.39 & & 0.93 & 0.40 & 0.51 & 0.86 & 1.11 & 0.94 & \\
\hline & DAL1 & 0.92 & -0.04 & 0.17 & 0.58 & 1.19 & 1.53 & & 0.32 & 0.00 & 0.59 & 1.35 & 1.73 & 1.78 & \\
\hline & GAT1 & 2.96 & 1.37 & 1.15 & 1.24 & 1.46 & 1.47 & & 1.65 & 1.07 & 1.03 & 1.23 & 1.32 & 1.23 & \\
\hline & \multirow[t]{2}{*}{ YBR139W } & 3.54 & 1.96 & 1.69 & 1.67 & 1.62 & 1.62 & & 0.40 & 1.43 & 1.13 & 1.12 & 1.12 & 1.05 & \\
\hline & & $1 \mathrm{~h}$ & $15 \mathrm{~h}$ & $27 \mathrm{~h}$ & $41 \mathrm{~h}$ & $53 \mathrm{~h}$ & $67 \mathrm{~h}$ & & $1 \mathrm{~h}$ & $15 \mathrm{~h}$ & $27 \mathrm{~h}$ & $41 \mathrm{~h}$ & $53 \mathrm{~h}$ & $67 \mathrm{~h}$ & \multirow{10}{*}{$\begin{array}{l}\text { Category } \\
\text { transport } \\
\text { transport } \\
\text { transport } \\
\text { transport } \\
\text { metabolism } \\
\text { metabolism } \\
\text { metabolism } \\
\text { regulation } \\
\text { regulation }\end{array}$} \\
\hline \multirow{9}{*}{$\frac{\frac{3}{3}}{5}$} & SUL1 & 1.58 & -0.14 & 1.36 & 2.82 & 3.06 & 3.02 & & 0.03 & -0.71 & -0.58 & -0.62 & -0.69 & -1.04 & \\
\hline & MUP1-1 & -0.38 & 0.22 & 1.47 & 2.35 & 2.42 & 2.70 & & -0.19 & -0.44 & -0.04 & 0.13 & 0.27 & -0.10 & \\
\hline & MUP3 & 2.18 & 0.26 & 0.83 & 1.59 & 1.17 & 1.01 & & 0.37 & 0.31 & 0.15 & 0.02 & -0.10 & -0.06 & \\
\hline & rCT1 & 0.60 & 0.55 & 1.00 & 1.32 & 1.39 & 1.49 & & 0.28 & 0.28 & 0.49 & 0.53 & 0.59 & 0.39 & \\
\hline & JLP1-1 & 0.52 & 0.91 & 1.78 & 5.08 & 5.10 & 4.54 & & 0.69 & 1.45 & 1.58 & 1.71 & 1.67 & 1.85 & \\
\hline & JLP1-2 & 1.95 & 0.17 & 0.41 & 3.83 & 4.09 & 3.98 & & 0.32 & -0.08 & -0.03 & 0.16 & 0.23 & -0.04 & \\
\hline & JLP1-3 & 1.24 & 0.51 & 0.79 & 3.89 & 4.13 & 3.81 & & 0.23 & 0.56 & 0.48 & 0.64 & 0.73 & 0.55 & \\
\hline & MET32 & 2.36 & 0.63 & 1.54 & 2.05 & 2.05 & 2.13 & & 0.74 & 0.78 & 0.69 & 0.80 & 0.78 & 0.58 & \\
\hline & MET4 & 1.74 & 0.51 & 0.88 & 1.17 & 1.31 & 1.41 & & 0.59 & 0.48 & 0.52 & 0.83 & 0.88 & 0.56 & \\
\hline
\end{tabular}

Indeed, this comparison revealed strong differences in sulfur content (2-112 $\mathrm{mM})$ and phosphorus levels (21$395 \mathrm{mM})$ in the batch medium $[5,16,18,19]$. Such differences, resulting in a high salt content of the medium, have already been shown to be problematic for cellular growth. Besides sulfur and phosphorus, we additionally analyzed nitrogen content. As ammonium serves as $\mathrm{pH}$ control and nitrogen source in P. pastoris bioreactor cultivations the supply is herewith strongly strain- and process-dependent and not directly comparable.

\section{Medium supplementation leads to improved biomass generation and influences $\mathrm{CpB}$-production}

Based on the transcriptomics data and comparison of media recipes we decided to supplement $P$. pastoris methanol-grown cultures with $\left(\mathrm{NH}_{4}\right)_{2} \mathrm{HPO}_{4}$ or $\left(\mathrm{NH}_{4}\right)_{2} \mathrm{SO}_{4}$. The supplements were added as pulses during the cultivation due to limited solubility in the methanol-feed medium. The added amounts represented the difference between the used medium and the BSM medium or the doubled amount $(2 \times)$, however, contrary to the BSM medium the supplements were not included into the batch medium but added as pulses during the fed batch phase. To evaluate the effects of the supplementations, we selected four potential marker genes per compound addressing different aspects of molecular function and exhibiting strong changes in transcript levels during the fed-batch process. Those genes were PHO5, PHO81, PHO84 and VTC1 for phosphorus limitation, JLP1-1, MET32, SUL1 and MUP1-1 for sulfur limitation, and DUR3-1, TPO2, PUT1, DAL1 for nitrogen limitation.

To see if the addition of phosphorus, sulfur or nitrogen can diminish the transcriptional upregulation and has an impact on biomass formation and productivity, bioreactor cultivations were performed in duplicates and analyzed for biomass generation (DCW) and production of secreted CpB. In Fig. 7 the biomass development of the reference culture and the supplemented cultures are shown. $1 \times$ or $2 \times \mathrm{SO}_{4}$-supplementation correlates with addition of 23 or $46 \mathrm{mM}$ sulfur and $1 \times \mathrm{PO}_{4}$-supplementation with $28 \mathrm{mM}$ additional phosphorus. Due to their limited solubility in methanol, 

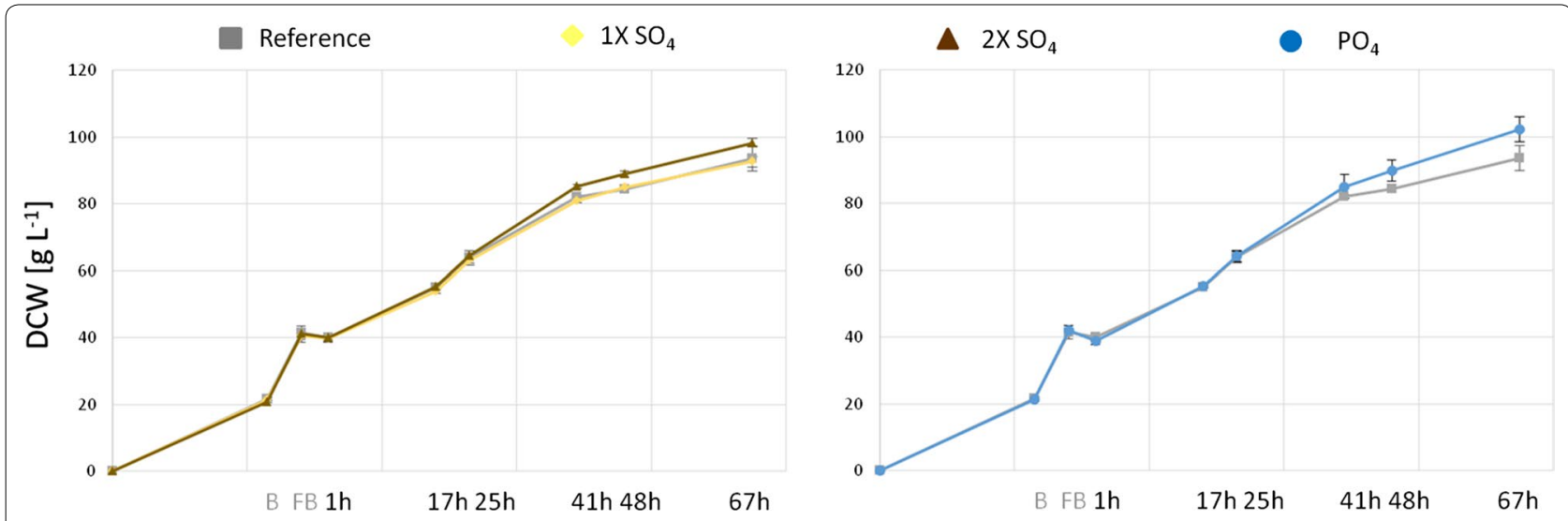

Fig. 7 Biomass generation (DCW) in the unsupplemented reference cultures, $1 \times \mathrm{SO}_{4}, 2 \times \mathrm{SO}_{4}$ - and $1 \times \mathrm{PO}_{4}$-supplemented culture. $B$ glycerol batch, FB glycerol fed-batch; 1-67 h methanol fed-batch. Error bars indicate standard deviation of the duplicate fed batch cultivations

supplements were given after each sampling, beginning with the end of the glycerol fed-batch. Biomass generation in biological replicates was reproducible and $2 \times \mathrm{SO}_{4}$ and $\mathrm{PO}_{4}$-supplemented cultures showed an improved growth with $4 \mathrm{~g} \mathrm{~L}^{-1}(5 \%)$ higher DCW in the $2 \times \mathrm{SO}_{4}$-supplemented cultures and $8 \mathrm{~g} \mathrm{~L}^{-1}(9 \%)$ higher $\mathrm{DCW}$ for the $\mathrm{PO}_{4}$-supplemented culture. $1 \times \mathrm{SO}_{4}$ supplementation did not lead to improved biomass generation.

$\mathrm{CpB}$-activity was determined in all culture supernatants (Fig. 8) using an enzymatic assay. As we used the constitutive $\mathrm{P}_{\mathrm{GAP}}$ promoter $\mathrm{CpB}$ levels are expected to increase during the whole process. In the reference cultivations (without any supplement) we observed a plateau in $\mathrm{CpB}$ activity during the later fed-batch and a final $\mathrm{CpB}$ titer of $136 \mathrm{mg} \mathrm{L}^{-1}$ on average. In the $1 \times \mathrm{SO}_{4}$-supplemented cultures product titers rose until $48 \mathrm{~h}$ of fed-batch, but then declined until the end of the process to levels slightly higher than the reference culture (148 $\mathrm{mg} \mathrm{L}^{-1}$; $9 \%$ improvement). In contrast, $2 \times \mathrm{SO}_{4}$-supplemented cultures reached $206 \mathrm{mg} \mathrm{L}^{-1} \mathrm{CpB}$ (52\% improvement) and $1 \times \mathrm{PO}_{4}$-supplemented cultures even $217 \mathrm{mg} \mathrm{L}^{-1} \mathrm{CpB}$ (60\% improvement). SDS-PAGEs confirmed the trend of the activity values. Viability of the cultures was measured at the end of the cultivations and remained comparably high $(>97 \%)$ in all cultivations.

\section{Sulfur and phosphorus supplementation cures upregulation of marker gene transcript levels during the fed batch}

Transcript levels of the potential nutrient limitation marker genes were determined by quantitative PCR (qPCR) in the reference culture (no supplement) and the supplemented cultures. Transcript levels at the middle $(27 \mathrm{~h})$ and the end $(67 \mathrm{~h})$ of the methanol fed-batch are shown as fold changes to the glycerol fed-batch in Fig. 9. In the reference cultures we were able to verify the

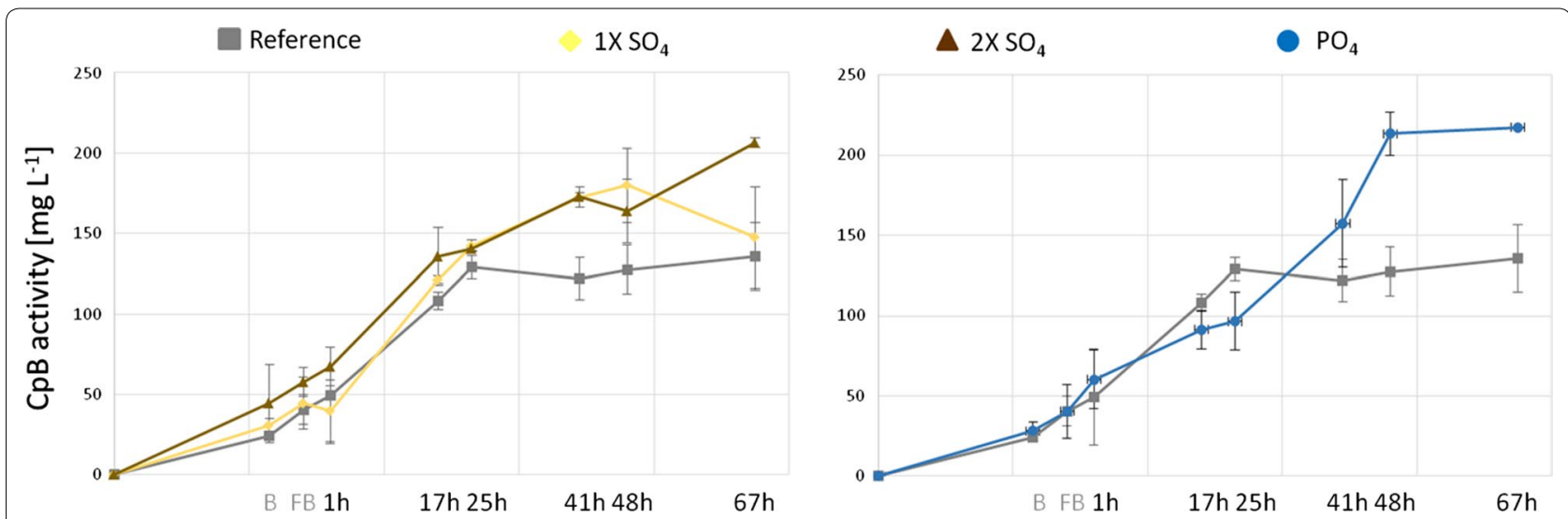

Fig. 8 Total $\mathrm{CpB}$-activity in the reference-, $1 \times \mathrm{SO}_{4^{-}}, 2 \times \mathrm{SO}_{4^{-}}$and $1 \times \mathrm{PO}_{4^{-}}$-supplemented fed-batch cultures. (B glycerol batch, FB glycerol fed-batch; 1-67 h methanol fed-batch). Error bars indicate standard deviation of the duplicate cultures 


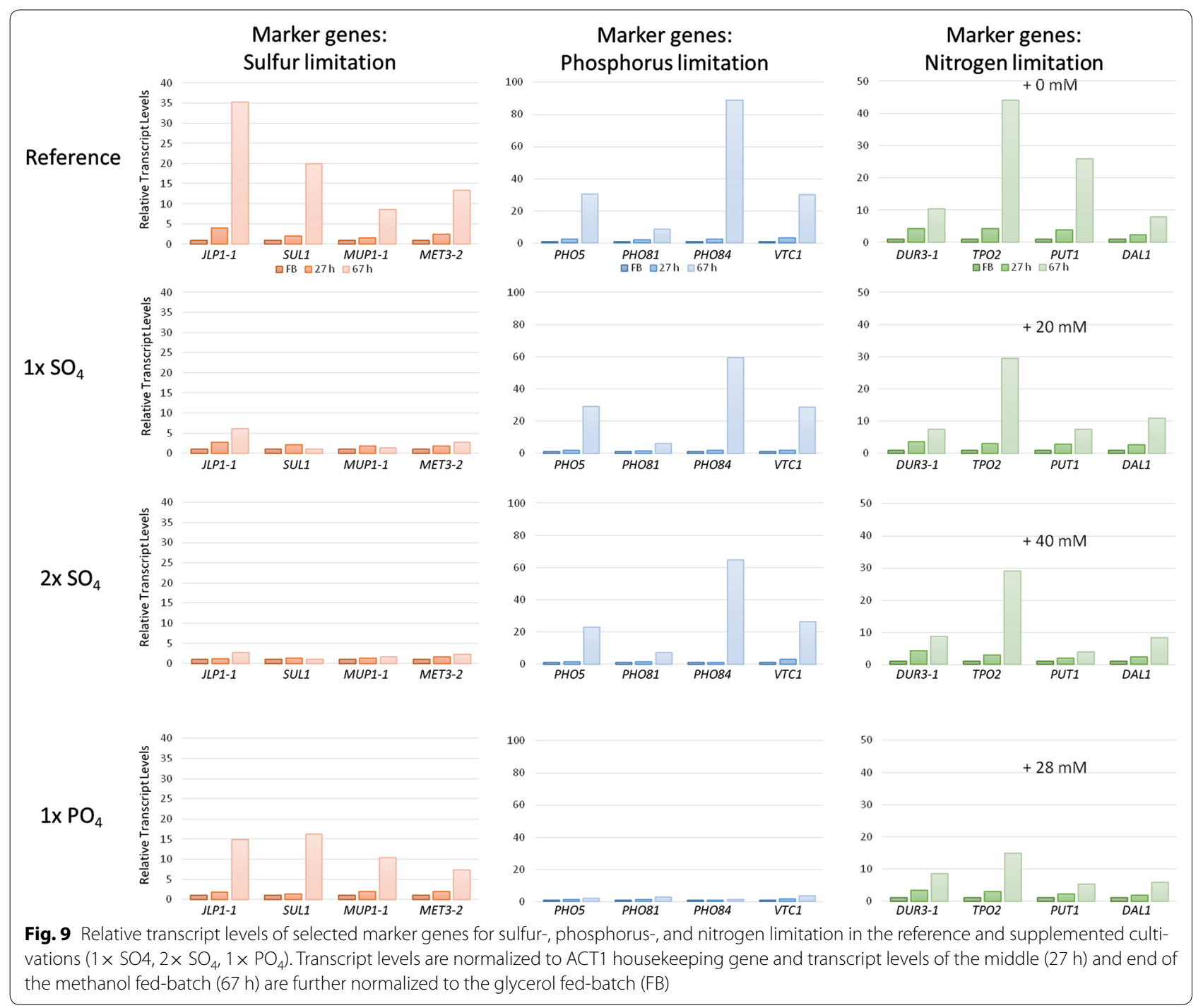

transcriptional regulatory patterns for the selected marker genes that were observed with microarrays in the previous cultivations. The strongest marker gene for sulfur limitation (JLP1-1) showed an increase of up to 35-fold from the middle to the end of fed-batch in the reference culture, and the other marker genes were 10- to 20-fold induced. Transcript levels of the strongest phosphorus limitation marker gene (PHO84) even increased up to about 89-fold, while PHO5 and VTC1 were approximately 30-fold upregulated.

In $1 \times\left(\mathrm{NH}_{4}\right)_{2} \mathrm{SO}_{4}$-supplemented cultures, upregulation of transcript levels of sulfur limitation marker genes was strongly reduced compared to the reference culture. By addition of the double amount $\left(\mathrm{NH}_{4}\right)_{2} \mathrm{SO}_{4}$ no upregulation was observed, and transcript levels were nearly suppressed to the levels of the glycerol fed-batch. Similarly, in $\left(\mathrm{NH}_{4}\right)_{2} \mathrm{HPO}_{4}$-supplemented cultures transcript level of phosphorus limitation marker genes were reduced to the glycerol fed-batch levels at the end of the methanol fed-batch. In order to exclude cross regulations between sulfur and phosphorus metabolism or regulation resulting from a general stress reactions we additionally analyzed the influence of $\left(\mathrm{NH}_{4}\right)_{2} \mathrm{HPO}_{4}$-supplementation on the transcript levels of sulfur limitation marker genes and vice versa. The transcript levels of phosphorus marker genes in the $1 \times$ and $2 \times \mathrm{SO}_{4}$-supplemented cultures behaved like the reference. Only for $\mathrm{PHO} 84$ the degree of induction seemed slightly lower, being 60 -fold higher on average. The addition of $\left(\mathrm{NH}_{4}\right)_{2} \mathrm{HPO}_{4}$ seemed to have a slight influence on the strenght of sulfur marker gene upregulation. At least for JLP1-1 transcript levels were less strongly upregulated (20-fold vs. 35 -fold in the reference culture), but overall the trends of regulation were unaffected (Fig. 9). 


\section{Nitrogen supplementation is not responsible for improved growth and $\mathrm{CpB}$ production}

Since we selected $\left(\mathrm{NH}_{4}\right)_{2} \mathrm{SO}_{4}$ and $\left(\mathrm{NH}_{4}\right)_{2} \mathrm{HPO}_{4}$ for increasing the sulfur or phosphorus-availability in the culture, an additional nitrogen source became available. We used these ammonium-based salts on the one hand to avoid further addion of metal ions and on the other hand to be able to analyze the transcriptional response of the identified potential nitrogen limitation marker genes upon nitrogen supplementation simultaneously. The given amounts of added nitrogen are referred to the total amount which has been added during the whole cultivation together with the respective $\mathrm{SO}_{4}$ or $\mathrm{PO}_{4}$ pulses [Reference: no additional nitrogen; $1 \times\left(\mathrm{NH}_{4}\right)_{2} \mathrm{SO}_{4}: 20 \mathrm{mM}$; $\left.2 \times\left(\mathrm{NH}_{4}\right)_{2} \mathrm{SO}_{4}: 40 \mathrm{mM} ; 1 \times\left(\mathrm{NH}_{4}\right)_{2} \mathrm{HPO}_{4}: 28 \mathrm{mM}\right]$. The nitrogen amount added in frame of the $\mathrm{pH}$-control during the cultivation was comparable for the reference and $\mathrm{SO}_{4}$-supplemented cultures $(33 \mathrm{~mL} \pm 4 \mathrm{~mL}$ of $25 \% \mathrm{NH}_{3}$ which is equal to $\left.364 \pm 44 \mathrm{mM}\right)$. Only the $\mathrm{PO}_{4}$-supplemented cultures received markedly less (21 mL; equal to $231 \mathrm{mM}$ ) during the cultivation. This calculation verifies that nitrogen addition in the course of $\left(\mathrm{NH}_{4}\right)_{2} \mathrm{SO}_{4}$ and $\left(\mathrm{NH}_{4}\right)_{2} \mathrm{HPO}_{4}$ supplementation can be neglected and that nitrogen is not the driving force for improved $\mathrm{CpB}$ production. The highest $\mathrm{CpB}$ levels were observed in $\left(\mathrm{NH}_{4}\right)_{2} \mathrm{HPO}_{4}$-supplemented cultures which received about $40 \%$ less nitrogen than $\left(\mathrm{NH}_{4}\right)_{2} \mathrm{SO}_{4}$-supplemented cultures.

In the reference culture e.g. transcript levels of polyamine transporter TPO2 was 45 -fold higher than in the glycerol fed-batch phase and was reduced to about tenfold higher levels in the $\left(\mathrm{NH}_{4}\right)_{2} \mathrm{HPO}_{4}$-supplemented culture. Also proline oxidase PUT1 levels decreased from $25 \times$ to less than $7 \times$ in all cultures with nitrogen supplementation. The transcript levels of DUR3-2 and DAL1 were not influenced. However, the neglectable nitrogen addition makes evaluation of marker gene regulation in respect of added nitrogen in frame of $\left(\mathrm{NH}_{4}\right)_{2} \mathrm{SO}_{4}$ and $\left(\mathrm{NH}_{4}\right)_{2} \mathrm{HPO}_{4}$ supplementation not possible.

\section{Discussion}

Upregulated high affinity transport systems and induction of alternative nutrient source utilization revealed limitations of phosphorus-, sulfur- and nitrogen during fed-batch cultivations of recombinant $P$. pastoris Sensing of culture conditions and adaptations of cellular metabolism to nutrient availability have been extensively studied in S. cerevisiae and have revealed that many cellular processes such as nutrient utilization, ribosome biogenesis, and stress responses are directly affected. As a result, cell cycle progression is modified [37]. In consequence, limitations in macronutrients or even starvation conditions might affect cellular growth and recombinant protein production (RPP) in yeast production platforms. To detect and overcome such limitations, different approaches for media optimization of complex or synthetic media for use in an industrially relevant setup have been experimentally tested. They were mainly based on host physiology and the fermentation performance [11]. Important considerations were the cellular composition of the host [38] but the impact of recombinant protein production in a relevant production process had not been considered. In the present work transcriptomics studies of a production process of the recombinant enzyme $\mathrm{CpB}$ in carbon-limited fed-batch cultivations of $P$. pastoris showed that methanol- and glucose-grown cultures experience transcriptional upregulation of genes connected to phosphorus and nitrogen metabolism from the middle to the end of the fed-batch. Unique for the methanol fed-batch was a strong upregulation of sulfur associated genes. The strong upregulation of the respective genes was not only clearly observed during the later methanol fed-batch, but also during the methanol induction phase. The mentioned genes are connected to transport processes and utilization of alternative substrates for coverage of the phosphorus- nitrogen-, and sulfur demand. Whereas gene regulation of phosphorus associated genes were similar between methanol and glucose fed-batch, upregulation of nitrogen associated genes was stronger on methanol and upregulation of sulfur-associated genes was only visible in the methanol fed-batch. Tracking those indications, principle component analysis (PCA) revealed connections to permanent limitations on macronutrient level which occur at high cell densities when nutrients are used up in the cellular environment which leads to upregulation of alternative pathways for coverage of respective demands.

The IAM medium was designed based on cellular composition of $P$. pastoris [26] and has successfully been used for production of several model proteins in P. pastoris $[8,19,39]$. Considerations for media development were a balanced composition based on the elemental composition of $P$. pastoris, comparably low, but sufficient salt concentration for growth, and suitability for downstream processing. Especially salt content and osmolarity can play an important role [21] as high salt concentration can inhibit growth [22] and herewith might also influence recombinant protein production. Furthermore, high salt concentrations make downstream processing more difficult [4]. Even proteolytic activity and consequently product stability in the supernatant can be influenced. By specific nutrient addition we intended to improve cellular growth and recombinant protein production by reduction of starvation-induced cellular changes which could reduce recombinant protein production on different levels $[40,41]$. 


\section{Growth on methanol has higher and different nutrient demand than glucose metabolization}

As metabolization of methanol is quite different to glucose consumption we were interested if such differences would result in a differing transcriptional response of selected marker genes. The observations indicate marked differences in the demand of nutrients even when developing equal biomass and using the same $P$. pastoris strain. This increased demand became even more obvious when analyzing the transcriptional response during the methanol induction phase where an increasing demand of respective nutrients was observed. When $P$. pastoris methanol metabolism is induced and the cells grow on methanol as sole carbon and energy source many cellular adaptations take place. They range from equipping the cell with the enzymatic apparatus for methanol metabolization [42] to organelle reconstruction (e.g. peroxisomes, vacuole, mitochondria) [36] which could lead to this increased nutrient and amino acid demand. These adaptations are also reflected by the higher protein content of methanol grown cells [33]. Furthermore there is a higher demand of cofactors, needed for growth on methanol. Among them, glutathione as redox regulator, representing a major cellular sulfur containing compound, is essential for prevention of cell damage. As glutathione levels are elevated in P. pastoris grown on methanol [43], compared to glucose, this could explain the high sulfur demand. Some cellular or metabolic changes during the adaptations to methanol might be only temporary and can be compensated by upregulation of transport processes to a certain point. However, the difference in the strength of upregulation between methanol and glucose grown cells in the later fed-batch can be caused by the early consumption of available nutrients during the methanol induction phase which makes the transcriptional response earlier and stronger. This implies that an appropriate media supplementation, especially for high producing strains like a $\mathrm{P}_{A O X 1^{-}}$-based expression system, could have an even stronger positive impact on growth and recombinant protein production compared to a $\mathrm{P}_{\mathrm{GAP}}$-based system. The higher load of recombinant protein synthesis and induced stress reactions could result in an even higher demand for the mentioned media components.

\section{Phosphorus}

Inorganic phosphate $(\mathrm{Pi})$ represents an important macronutrient for cellular metabolism in different purposes. Basically it is utilized for energy metabolism in terms of ATP generation but is also needed as cofactor for enzymes, nucleoproteins, or as intracellular buffer [44]. Phosphate homeostasis in S. cerevisiae can be divided into (1) transport processes of Pi or alternative substrates through the plasma membrane, (2) adaptation of the metabolism on transcriptional level by the PHO regulon, and (3) vacuolar release of inorganic phosphate. Uptake of Pi by yeast cells is mediated by a set of phosphatespecific transporters or cotransporters. The major storage organelle of excess phosphorus is the vacuole. Under limiting Pi levels, the PHO pathway becomes activated by Pho4 together with Pho2. This leads to increased expression of genes associated with acquisition, uptake and storage of Pi. The activity of Pho4 is regulated by the Pho80-Pho85 cyclin dependent kinase complex (CDK). In consequence, high affinity transporters (Pho84 and Pho89) are activated and low affinity transporters (Pho87 and Pho90) inactivated. Low affinity transporters are targeted to the vacuole and become degraded. Furthermore the VTC-complex is induced which leads to increased polyphosphate (polyP) synthesis in the vacuole. For usage of alternative Pi sources for growth, Gde1 hydrolyzes glycerophosphocholine into choline and glycerophosphate [44].

The described effects of high- (glycerol fed-batch phase) or low Pi-conditions (late methanol fed-batch) are reflected by the transcriptional regulation of potential phosphorus limitation marker genes observed in our study. Strong upregulation was seen for the genes encoding the high affinity phosphate transporters $\mathrm{PHO} 84$ and PHO89, a subunit of the VTC complex (VTC1) for release of $\mathrm{Pi}$ from the vacuole and GDE1 involved in generation of $\mathrm{Pi}$ from alternative substrates. As phosphorus is an essential nutrient, the impact of limitations on cellular growth have been investigated. In S. cerevisiae phosphorus limitation lead to a decreased phosphorus content in the cell, the cell wall composition was lower in glucans but with increased protein content, changes in lipid compositions occured [45], and even cell size changed [46]. Furthermore it is known that growth continues to a certain amount, dependent on the previous amount of available phosphorus in the medium [47], but permanent restriction can result in growth arrest [46] resulting in downregulation of many processes that might also be rate limiting for recombinant protein production and secretion.

\section{Sulfur}

Yeasts utilize sulfur for generation of sulfur amino acids and glutathione, which is acting as scavenger for oxygen free radicals. Metabolization occurs in frame of the assimilatory reduction from inorganic sulfur sources (e.g. sulfate) or organic sulfur sources (e.g. methionine). Uptake of sulfate is mediated by sulfate transport systems. Sulfate becomes reduced and then gets incorporated into organic compounds. As sulfur represents an essential nutrient, limitations in sulfur initially lead to 
upregulated transport into the cell, and in case of depletion of the preferred source of sulfur (inorganic, here sulfate) to uptake of alternative sulfur sources (organic sources). The uptake of sulfate is mediated, in dependency on its availability, by a high affinity and a lowaffinity uptake system. In conditions with sulfur excess, glutathione can act as storage form and can be used under sulfur limitation for biosynthesis of sulfur containing amino acids $[48,49]$.

In this study, an increased sulfur demand on transcriptional level was observed at the beginning and in the later methanol fed-batch, but not during the glucose fed-batch. Genes with respective regulation were SUL1, JLP1-1, MUP1-1, MUP3, MET4, MET32, and YCT1. Sul1 represents a high affinity sulfate permease which controls the concentration of endogenous activated sulfate intermediates $[50,51]$ and is highly induced upon sulfate starvation in S. cerevisiae [31]. Jlp1 is a sulfonate/alpha-ketoglutarate dioxygenase involved in sulfonate catabolism for use as a sulfur source which is induced by sulfur starvation [52, 53]. Mup1 represents a high affinity methionine permease which is also involved in cysteine uptake [54] and was highly upregulated under sulfur starvation in S. cerevisiae [31]. Transcriptional regulation of MET-genes as occurring $1 \mathrm{~h}$ after the start of the methanol-feed was already described in correlation to methanol metabolism in $P$. pastoris [55]. The regulatory pattern observed towards the end of the fed-batch is not necessarily connected to the methanol metabolism as Met4 is the only transcriptional activator of sulfur metabolism [56] and upregulation of MET4 and MET32, a transcription factor involved in transcriptional regulation of the methionine biosynthetic pathway was described under sulfur starvation in S. cerevisiae [31]. Similar gene regulations were also observed in Yarrowia lipolytica [57]. Based on these results we selected ILP1-1, SUL1, MUP1-1 and MET32 as potential limitation markers in fed-batch cultivations. Respective supplementation led to strongly reduced transcript levels of all selected marker genes at the end of the fed batch, which were dose-dependent $(1 \times, 2 \times$ sulfur supplementation), and also had a positive impact on biomass generation and $\mathrm{CpB}$ levels in culture supernatants. A connection between sulfur limitation and the impact on biomass formation is given since sulfur metabolic flux is correlated to growth rate and it can have impact on initiation of cell division in S. cerevisiae [58]. In Trichoderma reesei it was even proposed that during recombinant protein production, which requires increased methionine and cysteine levels, sulfur assimilation could be limiting [59].

\section{Nitrogen}

Microbial cellular compounds containing nitrogen are mainly amino acids, purines and pyrimidines. Yeasts are able to utilize different nitrogen sources to cover their demand. In S. cerevisiae nitrogen can be taken up e.g. in form of urea and ammonium or as amino acids (proline or arginine). The quality of the nitrogen source further determines the maximum growth rate and has profound impact on cellular growth. For the biosynthesis of nitrogenous compounds, the potential nitrogen sources are further metabolized to glutamate or glutamine [60]. Contrary to other methylotrophic yeasts, P. pastoris cannot assimilate nitrate [61], and is also deficient in utilization of urea.

Depending on the availability of a preferred nitrogen source (excess or limitation) or a non-preferred nitrogen source, respective pathways for homeostasis of nitrogen are regulated. Upon limitation, upregulated cellular functions are associated with the vacuole, cell cycle, and organelle organization/biogenesis. The transcriptional response of a nitrogen-limited culture is similar to the nitrogen catabolite repression and results in upregulation of several pathways. These pathways are the allantoin pathway (DAL genes), proline utilization genes (PUT1/2), glutamate metabolizing genes (GLT1/GDH1), and genes for amino acid and ammonium transporters (as GAP1, $M E P 2, V B A 1, A V T 1 / 4)$ [62]. In our dataset we additionally observed a marked upregulation of TPO2, a polyamine transporter, responsible for the uptake of polyamines as alternative substrate for covering the nitrogen demand. Supplementation with different amounts of nitrogen in form of $\left(\mathrm{NH}_{4}\right)_{2} \mathrm{HPO}_{4}$ or $\left(\mathrm{NH}_{4}\right)_{2} \mathrm{SO}_{4}$ led to decreased transcript levels of TPO2, PUT1 but did not affect DUR31 , and DAL1. In the described and analyzed processes, additional nitrogen supply in the course of sulfur and phosphorus supplementation did not play a major role but should nevertheless be considered as crucial as it has been reported that nitrogen availability and the type of nitrogen source has an effect on gene expression strength of MUT and PEX genes in P. pastoris [63]. Furthermore nitrogen starvation was found to affect ribosomal protein production [62], their degradation [23] and to slow down translation rates [64]. Also, degradation of already secreted proteins could become an issue since expression and secretion of proteases takes place in nitrogen limited conditions [65] which could also affect product stability in culture supernatants [66].

\section{Conclusions}

Transcriptomics analyses have shown that sulfur-, phosphorus- and nitrogen limitation occur in common methanol- or glucose-limited fed-batch processes of recombinant $P$. pastoris, being more pronounced in the methanol fed-batch. We identified biomarkers for these nutrient limitations, that can be versatily used for monitoring potential deficiencies occurring during production 
processes. Using qPCR of these marker genes as novel method for detection of nutrient limitations we were able to rectify such limitations on transcriptional level by addition of $\left(\mathrm{NH}_{4}\right)_{2} \mathrm{HPO}_{4}$ or $\left(\mathrm{NH}_{4}\right)_{2} \mathrm{SO}_{4}$. Sulfur and phosphorus supplementation but not nitrogen addition led to improved cellular growth and recombinant protein production. This approach is not limited to processes for recombinant protein production, but can be also used for other strains or production hosts as the need for tailor-made cultivation media is emerging. Applicability, especially for high producing cell lines, is conceivable as stress levels increase the demand for optimal culture conditions. In this regards, an appropriate supplementation can lead to improved recombinant protein production by diminishing the higher metabolic burden due to the strong production of recombinant protein.

\section{Methods}

\section{Strain}

Pichia pastoris (Komagataella phaffii) CBS7435 Mut $^{+}$ (methanol utilization plus phenotype), producing porcine pro-carboxypeptidase $\mathrm{B}(\mathrm{CpB})$ as model protein under the control of the $\mathrm{P}_{\mathrm{GAP}}$ promoter and the $S$. cerevisiae alpha mating factor as secretion signal, was selected for the described bioreactor cultivations.

\section{Fed batch cultivations}

The preculture $\left(100 \mathrm{~mL}\right.$ YPG $+50 \mu \mathrm{g} \mathrm{mL}^{-1}$ Zeocin) was inoculated using a $1 \mathrm{~mL}$ cryo stock and was cultivated overnight at $150 \mathrm{rpm}$. The exponentially growing culture was washed (glycerol batch medium) and used for inoculation of the bioreactor culture to OD 1. Bioreactor cultivations were performed in a $2.7 \mathrm{~L}$ DASGIP bioreactor with a batch volume of $1.225 \mathrm{~L}$ for the inital cultivations used for transcriptomics analyses, or in $1 \mathrm{~L}$ bioreactors with a batch volume of 0.325 L (DASGIP Parallel Bioreactor System, Germany) for the other cultivations. The fed-batch process comprised four phases, starting with a glycerol-batch phase. The initial cultivations for microarray analyses were performed using the following setup:

After reaching the batch end at about $24 \mathrm{~h}$, a carbon limited glycerol fed-batch for $5 \mathrm{~h}$ was started with a feed rate of $5.5 \mathrm{~g} \mathrm{~L}^{-1} \mathrm{~h}^{-1}$ to reach a biomass of $40 \mathrm{~g} \mathrm{~L}^{-1}$ dry cell weight $(\mathrm{DCW})$. Methanol-grown cultures were then supplemented with $0.5 \%(\mathrm{w} / \mathrm{v})$ methanol for induction of methanol metabolism. After consumption of the methanol shot, a methanol fed-batch was started and cultures were grown for $67 \mathrm{~h}$ to reach a final biomass of $100 \mathrm{~g} \mathrm{~L}^{-1}$. The glucose fed-batch was started with an initial feed rate of $1.9 \mathrm{~g} \mathrm{~L}^{-1} \mathrm{~h}^{-1}$ for $4 \mathrm{~h}$ to generate the same biomass as the methanol shotted cultures. The feed rate of the methanol- or glucose fed-batch medium during the fed-batch was increased after $14 \mathrm{~h}$ (methanol FB: initial feed rate
$6.8 \mathrm{~g} \mathrm{~L}^{-1} \mathrm{~h}^{-1}$, feed increase after $12 \mathrm{~h}$ to $9.0 \mathrm{~g} \mathrm{~L}^{-1} \mathrm{~h}^{-1}$; glucose FB: initial feed rate $9.9 \mathrm{~g} \mathrm{~L}^{-1} \mathrm{~h}^{-1}$, feed increase after $14 \mathrm{~h}$ to $13.2 \mathrm{~g} \mathrm{~L}^{-1} \mathrm{~h}^{-1}$ ). Due to insolubility of salts (see salt shots and supplements) in the methanol fedbatch medium, methanol and glucose grown cultures were supplemented with respective amounts representing a surplus for generation of about $10 \mathrm{~g}$ yeast biomass (DCW).

The initial cultivations were performed in triplicates at $25{ }^{\circ} \mathrm{C}$. Dissolved oxygen was controlled at $20 \%$, and $\mathrm{pH}$ was adjusted to 5 by $25 \% \mathrm{NH}_{3}$. Foam formation was prevented by addition of Glanapon 2000 (5\%; Bussetti \& Co $\mathrm{GmbH}$, Austria) upon demand using a level probe. Samples were taken at the batch end, at the end of the glycerol fed-batch, and 1, 15, 27 41, 53 and $67 \mathrm{~h}$ after starting the methanol- and glucose fed-batch.

The cultivations for media supplementation were performed in duplicates and were carried out at the same setpoints. The fed-batch process was performed identically to the initial cultivations, only the feed-rate during the fed-batches were adapted to the smaller scale. During the methanol fed-batch, the cultures were supplemented with a sulfur and/or phosphorus source after each sampling.

\section{Cultivation media and supplements}

Preculture medium contained per liter: $20 \mathrm{~g}$ soy peptone and $10 \mathrm{~g}$ yeast extract. Sterile glycerol stock was added after heat sterilization in autoclave $\left(121^{\circ} \mathrm{C}, 20 \mathrm{~min}\right)$ for a final glycerol concentration of $1.26 \%$. Zeocin was used as selective agent $\left(50 \mu \mathrm{g} \mathrm{mL}^{-1}\right)$.

Glycerol batch medium (IAM) contained per liter: $2 \mathrm{~g}$ citric acid monohydrate, $45.6 \mathrm{~g}$ glycerol $(86 \%), 12.6 \mathrm{~g}$ $(\mathrm{NH} 4)_{2} \mathrm{HPO}_{4}, 0.5 \mathrm{~g} \mathrm{MgSO}_{4} \cdot 7 \mathrm{H}_{2} \mathrm{O}, 0.9 \mathrm{~g} \mathrm{KCl}, 0.022 \mathrm{~g}$ $\mathrm{CaCl}_{2} \cdot 2 \mathrm{H}_{2} \mathrm{O}, 2 \mathrm{~mL}$ biotin $\left(0.2 \mathrm{~g} \mathrm{~L}^{-1}\right)$ and $4.6 \mathrm{~mL}$ PTM trace salts stock solution. $\mathrm{HCl}$ was used to set the $\mathrm{pH}$ to 5.0.

Glycerol fed-batch medium (GLY01) contained per liter: $724.4 \mathrm{~g}$ glycerol (86\%), $12 \mathrm{~mL}$ PTM and $2 \mathrm{~mL}$ biotin $\left(0.2 \mathrm{~g} \mathrm{~L}^{-1}\right)$.

Methanol fed-batch medium (MET01) contained per liter: $835.1 \mathrm{~mL}$ pure methanol, $12 \mathrm{~mL}$ PTM, and $2 \mathrm{~mL}$ biotin $\left(0.2 \mathrm{~g} \mathrm{~L}^{-1}\right)$.

Glucose fed-batch medium (GLU04) contained per liter: $464.4 \mathrm{~g} \mathrm{~L}^{-1}$ glucose monohydrate, $12 \mathrm{~mL}$ PTM, and $2 \mathrm{~mL}$ biotin $\left(0.2 \mathrm{~g} \mathrm{~L}^{-1}\right)$.

PTM trace salts stock solution contained per liter: $6.0 \mathrm{~g} \mathrm{CuSO}_{4} \cdot 5 \mathrm{H}_{2} \mathrm{O}, 0.08 \mathrm{~g} \mathrm{NaI}, 3.0 \mathrm{~g} \mathrm{MnSO}_{4} \cdot \mathrm{H}_{2} \mathrm{O}, 0.2 \mathrm{~g}$ $\mathrm{Na}_{2} \mathrm{MoO}_{4} \cdot 2 \mathrm{H}_{2} \mathrm{O}, 0.02 \mathrm{~g} \mathrm{H}_{3} \mathrm{BO}_{3}, 0.5 \mathrm{~g} \mathrm{CoCl}_{2}, 20.0 \mathrm{~g} \mathrm{ZnCl}_{2}$, $5.0 \mathrm{~g} \mathrm{FeSO}_{4} \cdot 7 \mathrm{H}_{2} \mathrm{O}$, and $5.0 \mathrm{~mL} \mathrm{H}_{2} \mathrm{SO}_{4}(95-98 \% \mathrm{w} / \mathrm{w})$.

Salt shots contained per liter: $13.9 \mathrm{~g} \mathrm{MgSO}_{4} \cdot 7 \mathrm{H}_{2} \mathrm{O}$, $27.7 \mathrm{~g} \mathrm{KCl}$ and $0.69 \mathrm{~g} \mathrm{CaCl}_{2} \cdot 2 \mathrm{H}_{2} \mathrm{O}$. For solubility reasons in methanol fed-batch medium, respective salts were 
provided in shots $(22.5 \mathrm{~mL})$ for the reference culture or got combined with respective supplements for the sulfur and phosphorus-supplemented cultures.

Sulfur supplement and common salt shot were prepared as one solution which contained per liter: $91.5 \mathrm{~g}$ $\left(\mathrm{NH}_{4}\right)_{2} \mathrm{SO}_{4}, 13.9 \mathrm{~g} \mathrm{MgSO}_{4} \cdot 7 \mathrm{H}_{2} \mathrm{O}, 27.7 \mathrm{~g} \mathrm{KCl}$, and $0.69 \mathrm{~g}$ $\mathrm{CaCl}_{2} \cdot 2 \mathrm{H}_{2} \mathrm{O}$. Sulfur supplements were pulsed at 6 time points $(22.5 \mathrm{~mL})$ during the fed-batch process directly after a sampling.

Phosphorus supplement was prepared and added separately from common salt shot due to insolubility of $\left(\mathrm{NH}_{4}\right)_{2} \mathrm{HPO}_{4}$ in the common salt shot. Phosphorus supplement contained per liter: $392 \mathrm{~g}\left(\mathrm{NH}_{4}\right)_{2} \mathrm{HPO}_{4}$. The common salt shot contained per liter: $20.8 \mathrm{~g}$ $\mathrm{MgSO}_{4} \cdot 7 \mathrm{H}_{2} \mathrm{O}, 41.6 \mathrm{~g} \mathrm{KCl}$, and $1.04 \mathrm{~g} \mathrm{CaCl} \cdot 2 \mathrm{H}_{2} \mathrm{O}$. Phosphorus supplements were pulsed at 6 time points (7.5 mL) together with $15 \mathrm{~mL}$ common salt shot during the fed-batch process directly after a sampling.

\section{Biomass determination}

Dry cell weight (DCW) was determined in triplicates by sampling of $2 \mathrm{~mL}$ cell suspension into pre-weighed and pre-incubated $\left(1 \mathrm{~d}, 100{ }^{\circ} \mathrm{C}\right)$ reaction tubes and subsequent washing of cell pellet. DCW was determined after 3 days of drying at $100{ }^{\circ} \mathrm{C}$.

\section{Enzymatic CpB assay}

Quantification of recombinant product in culture supernatants was done using an enzymatic assay detecting $\mathrm{CpB}$-activity. Prior to activity determination, supernatants were desalted using Zeba ${ }^{\mathrm{TM}}$ Spin columns (ThermoFisher Scientific, $2 \mathrm{~mL}, 7 \mathrm{~K} \mathrm{MWCO}$ ) and pro$\mathrm{CpB}$ was activated by trypsin $\left(30 \mathrm{~min}, 37^{\circ} \mathrm{C}\right)$. Due to the very sensitive assay principle, reactions were performed in cuvettes and $\mathrm{CpB}$-activity was measured by the spectrophotometric method of Folk et al. [67] where the reaction velocity is determined by an increase in absorbance at $254 \mathrm{~nm}$ resulting from the hydrolysis of hippuryl-L-arginine. One unit $\mathrm{CpB}$ causes the hydrolysis of $1 \mu \mathrm{mol}$ of hippuryl-L-arginine per minute at $25^{\circ} \mathrm{C}$ and $\mathrm{pH}$ 7.65. All samples were measured in triplicates and activity was correlated to product concentrations using a $\mathrm{CpB}$ standard ranging from 0 to $69 \mathrm{mg} \mathrm{L}^{-1}$.

\section{SDS-PAGE}

Qualitative analysis of culture supernatants was performed by sodium dodecyl sulfate-polyacrylamide gel electrophoresis (SDS-PAGE) using the NuPAGE Bis-Tris system (MOPS buffer). Samples were heat denatured $\left(10^{\prime}, 95^{\circ} \mathrm{C}\right)$ and reduced. A BenchMark ${ }^{\mathrm{TM}}$ Protein Ladder (Thermo Fisher Scientific) was used. Proteins were separated $(180 \mathrm{~V}, 70 \mathrm{~min})$ and stained using PageBlue ${ }^{\mathrm{TM}}$
Protein Staining Solution (Thermo Fisher Scientific). After electrophoresis the gel was washed 3 times with deionized water, followed by staining with Coomassie brilliant blue and destained with deionized water.

\section{Viability measurements}

Culture viability was determined using a flow cytometrybased method (BD ${ }^{\mathrm{TM}}$ Cell Viability kit). Bioreactor samples were stored on ice and cells were then separated by ultrasonication $(3 \times 6 \mathrm{~s}, 85 \%$ amplitude $)$ and stained with propidium iodide. Flow cytometric analysis was performed at a Gallios ${ }^{\mathrm{TM}}$ cytometer (Beckman Coulter).

\section{Microarray experiments}

Total RNA was isolated from phenol/ethanol-fixated cells using TRI reagent according to the supplier's instructions (Ambion, USA). Isolated RNA was quantified by Nanodrop and integrity determined by Bioanalyzer (Agilent) or gel electrophoresis. For analysis of gene regulation with DNA-microarray, RNA was labelled with the fluorescent dyes $\mathrm{Cy} 3$ and $\mathrm{Cy} 5$, transcribed to CDNA, then to cRNA and finally purified (according to Two-Color Microarray-Based Gene Expression Analysis manual, Agilent). After a final quality control (integrity and labelling efficiency) cRNAs were hybridized to P. pastorisspecific microarray glass slides (8x15k-array, AMAD-ID: G2509F, Agilent), together with a reference pool-cRNA sample, and fluorescence intensity was measured via microarray scanner (Agilent). Raw data were normalized using variance stabilising normalisation (VSN) using the $\mathrm{R}$-platform and then integrated into the $P$. pastoris database [68].

Normalization steps and statistical analysis of microarray data included removal of color bias using locally weighted MA-scatterplot smoothing (LOESS) followed by between array normalization using the "Aquantile" method. The $\mathrm{P}$ values associated with the differential expression values were calculated using a linear model fit (limma $\mathrm{R}$ package), subsequently they were adjusted for multiple testing using the method of Benjamini and Yekutieli [69] using the BY method of limma R package. To identify differentially expressed genes, the following criteria were applied: fold change cut-off of at least $1.5>\mathrm{FC}>1 / 1.5$ and adjusted $\mathrm{P}$ value $<0.05$. All steps were performed using the R-software package [70], and the limma package.

\section{Principle component analysis (PCA)}

Principle component analysis was performed on the microarray dataset present in $\log _{2} \mathrm{FC}$ referred to the glycerol fed-batch phase using the Microsoft Excel plugin XLSTAT. 


\section{Quantitative real-time PCR}

Quantitative RT-PCR was used for transcript level determination of the reference cultivations and supplemented cultures. RNA from phenol/ethanol fixed samples was isolated, quantified and integrity was checked by agarose gel electrophoresis. After DNase treatment, RNA was transcribed to cDNA using the SensiMix SYBR Kit (QT605-05, Bioline, UK). Analysis was performed at a Rotor Gene 6000 real-time PCR cycler (Qiagen, DE). All samples were analyzed in tri- or quadruplicates.

The used protocol includes the following steps:

1. Hold $\left(95^{\circ} \mathrm{C} ; 10 \mathrm{~min}\right), 2$. Cycling ( 45 repeats including denaturation: $95{ }^{\circ} \mathrm{C} ; 15 \mathrm{~s}$, primer annealing: $60{ }^{\circ} \mathrm{C} ; 20 \mathrm{~s}$, and elongation: $\left.72{ }^{\circ} \mathrm{C} ; 15 \mathrm{~s}\right)$, and 3 . Melting $\left(65^{\circ} \mathrm{C} ; 90 \mathrm{~s}\right.$; Ramp from 65 to $99^{\circ} \mathrm{C}$ incrementally increased by $0.5^{\circ} \mathrm{C}$ (each $2 \mathrm{~s}$ ).

The occurrence of primer dimers and the purity of the PCR product were checked by melting curve analysis and raw data were normalized against $A C T 1$ as housekeeping gene and referenced to the sample of the glycerol fedbatch (according to the double delta Ct method for relative quantification [71]). Primer sequences can be found in the Additional file 1: Table S3.

\section{Additional file}

Additional file 1: Figure S1. Mean expression values (microarray data) of the carboxypeptidase B gene during the methanol and glucose fed-batch process. Table S2. Description of biological function of marker genes adapted from Saccharomyces Genome Database (SGD). Table S3. GPCR primer sequences. Figure S4. Principal component analysis (variable factor map; F2 vs. F1) of the methanol fed-batch ( $1 \mathrm{~h}, 15 \mathrm{~h}, 27 \mathrm{~h}, 41 \mathrm{~h}, 53 \mathrm{~h}$ and $67 \mathrm{~h}$ after starting the methanol fed-batch) referred to the glycerol fed-batch ( $\log _{2}$ fold change). Figure S5. Principal component analysis (variable factor map; F3 vs. F2) of the methanol fed-batch (1 h, 15 h, $27 \mathrm{~h}$, $41 \mathrm{~h}, 53 \mathrm{~h}$ and $67 \mathrm{~h}$ after starting the methanol fed-batch) referred to the glycerol fed-batch ( $\log _{2}$ fold change). Figure S6. Principal component analysis (variable factor map; F2 vs. F1) of the glucose fed-batch (1 h, $15 \mathrm{~h}$, $27 \mathrm{~h}, 41 \mathrm{~h}, 53 \mathrm{~h}$ and $67 \mathrm{~h}$ after starting the glucose fed-batch) referred to the glycerol fed-batch ( $\log _{2}$ fold change). Figure S7. Principal component analysis (variable factor map; F3 vs. F2) of the glucose fed-batch (1 h, $15 \mathrm{~h}$, $27 \mathrm{~h}, 41 \mathrm{~h}, 53 \mathrm{~h}$ and $67 \mathrm{~h}$ after starting the glucose fed-batch) referred to the glycerol fed-batch ( $\log _{2}$ fold change).

\section{Abbreviations}

RPP: recombinant protein production; $\mathrm{CpB}$ : pro-carboxypeptidase B; BSM: basal salt medium; DOE: design of experiments; PCA: principle component analysis; DCW: dry cell-weight; Pi: inorganic phosphate; VSN: variance stabilizing normalization.

\section{Authors' contributions}

JB performed all bioreactor cultivations, experimental work and data analysis, and participated in study design. ABG performed bioinformatics raw data analysis. MV supported functional gene annotations and data interpretation. $\mathrm{BG}$ and DM designed and conceived the study. JB, BG and DM wrote the manuscript. All authors read and approved the final manuscript.

\section{Author details}

${ }^{1}$ Austrian Centre of Industrial Biotechnology, Vienna, Austria. ${ }^{2}$ Department of Biotechnology, BOKU-University of Natural Resources and Life Sciences,
Muthgasse 18, 1190 Vienna, Austria. ${ }^{3}$ School of Bioengineering, University of Applied Sciences FH Campus Vienna, Vienna, Austria.

\section{Acknowledgements}

The authors thank Hubert Schwarz and Elisabeth Rebhan for their practical support during bioreactor cultivations and transcript level determination. Vienna Business Agency and EQ BOKU VIBT GmbH are acknowledged for providing fermentation equipment though the VIBT-Extremophile Center.

\section{Competing interests}

The authors declare that they have no competing interests.

\section{Availability of data and materials}

All data generated in this study are included in the article and its Additional file 1.

\section{Funding}

This work has been supported by the Austrian Federal Ministry of Science, Research and Economy (BMWFW), the Federal Ministry of Traffic, Innovation and Technology (bmvit), the Styrian Business Promotion Agency SFG, the Standortagentur Tirol, the Government of Lower Austria and ZIT-Technology Agency of the City of Vienna as well as Biocrates Life Sciences, Biomin, Boehringer Ingelheim, Lonza, Sandoz, and VTU Technology through the Austrian FFG-COMET-Funding Program.

\section{Publisher's Note}

Springer Nature remains neutral with regard to jurisdictional claims in published maps and institutional affiliations.

Received: 7 April 2017 Accepted: 28 June 2017

Published online: 11 July 2017

\section{References}

1. Mattanovich D, Branduardi P, Dato L, Gasser B, Sauer M, Porro D. Recombinant protein production in yeasts. In: Lorence $A$, editor. Recombinant gene expression. Totowa: Humana Press; 2012. p. 329-58.

2. Komar AA. The art of gene redesign and recombinant protein production: approaches and perspectives. Berlin: Springer Berlin Heidelberg; 2016. p. 1-17.

3. Idiris $\mathrm{A}$, Tohda $\mathrm{H}$, Kumagai $\mathrm{H}$, Takegawa K. Engineering of protein secretion in yeast: strategies and impact on protein production. Appl Microbiol Biotechnol. 2010:86:403-17.

4. Jahic M, Veide A, Charoenrat T, Teeri T, Enfors SO. Process technology for production and recovery of heterologous proteins with Pichia pastoris. Biotechnol Prog. 2006;22:1465-73.

5. Kobayashi K, Kuwae S, Ohya T, Ohda T, Ohyama M, Ohi H, Tomomitsu K, Ohmura T. High-level expression of recombinant human serum albumin from the methylotrophic yeast Pichia pastoris with minimal protease production and activation. J Biosci Bioeng. 2000;89:55-61.

6. Dragosits M, Stadlmann J, Albiol J, Baumann K, Maurer M, Gasser B, Sauer M, Altmann F, Ferrer P, Mattanovich D. The effect of temperature on the proteome of recombinant Pichia pastoris. J Proteome Res. 2009:8:1380-92.

7. Jahic M, Wallberg F, Bollok M, Garcia P, Enfors SO. Temperature limited fed-batch technique for control of proteolysis in Pichia pastoris bioreactor cultures. Microb Cell Fact. 2003;2:6.

8. Baumann K, Maurer M, Dragosits M, Cos O, Ferrer P, Mattanovich D. Hypoxic fed-batch cultivation of Pichia pastoris increases specific and volumetric productivity of recombinant proteins. Biotechnol Bioeng. 2008; 100:177-83

9. Looser V, Bruhlmann B, Bumbak F, Stenger C, Costa M, Camattari A, Fotiadis D, Kovar K. Cultivation strategies to enhance productivity of Pichia pastoris: a review. Biotechnol Adv. 2015;33:1177-93.

10. Almo SC, Love JD. Better and faster: improvements and optimization for mammalian recombinant protein production. Curr Opin Struct Biol. 2014;26:39-43. 
11. Hahn-Hägerdal B, Karhumaa K, Larsson CU, Gorwa-Grauslund M, Görgens J, van ZyIWH. Role of cultivation media in the development of yeast strains for large scale industrial use. Microb Cell Fact. 2005;4:31.

12. Cos O, Ramón R, Montesinos J, Valero F. Operational strategies, monitoring and control of heterologous protein production in the methylotrophic yeast Pichia pastoris under different promoters: a review. Microb Cell Fact. 2006;5:17.

13. Görgens JF, van Zyl WH, Knoetze JH, Hahn-Hägerdal B. Amino acid supplementation improves heterologous protein production by Saccharomyces cerevisiae in defined medium. Appl Microbiol Biotechnol. 2005;67(5):684-91.

14. Higgins DR, Cregg JM. Pichia protocols. Totowa: Humana Press; 1998.

15. Zhang $W$, Inan $M$, Meagher MM. Fermentation strategies for recombinant protein expression in the methylotrophic yeast Pichia pastoris. Biotechnol and Bioprocess Eng. 2000;5:275-87.

16. Zhao W, Wang J, Deng R, Wang X. Scale-up fermentation of recombinant Candida rugosa lipase expressed in Pichia pastoris using the GAP promoter. J Ind Microbiol Biotechnol. 2008;35:189-95.

17. d'Anjou MC, Daugulis AJ. Mixed-feed exponential feeding for fedbatch culture of recombinant methylotrophic yeast. Biotechnol Lett. 2000;22:341-6.

18. Stratton J, Chiruvolu V, Meagher M. High cell-density fermentation. Methods Mol Biol. 1998;103:107-20

19. Maurer M, Kuhleitner M, Gasser B, Mattanovich D. Versatile modeling and optimization of fed batch processes for the production of secreted heterologous proteins with Pichia pastoris. Microb Cell Fact. 2006;5:37.

20. Ghosalkar A, Sahai V, Srivastava A. Optimization of chemically defined medium for recombinant Pichia pastoris for biomass production. Bioresour Technol. 2008;99:7906-10.

21. Dragosits M, Mattanovich D, Gasser B. Induction and measurement of UPR and osmotic stress in the yeast Pichia pastoris. Methods Enzymol. 2011;489:165-88.

22. Melamed D, Pnueli L, Arava Y. Yeast translational response to high salinity: global analysis reveals regulation at multiple levels. RNA. 2008;14:1337-51.

23. Kraft C, Deplazes A, Sohrmann M, Peter M. Mature ribosomes are selectively degraded upon starvation by an autophagy pathway requiring the Ubp3p/Bre5p ubiquitin protease. Nat Cell Biol. 2008;10:602-10.

24. Mayer C, Grummt I. Ribosome biogenesis and cell growth: mTOR coordinates transcription by all three classes of nuclear RNA polymerases. Oncogene. 2006;25:6384-91.

25. Martin DE, Powers T, Hall MN. Regulation of ribosome biogenesis: where is TOR? Cell Metab. 2006;4:259-60.

26. Carnicer M, Baumann K, Töplitz I, Sánchez-Ferrando F, Mattanovich D, Ferrer P, Albiol J. Macromolecular and elemental composition analysis and extracellular metabolite balances of Pichia pastoris growing at different oxygen levels. Microb Cell Fact. 2009;8:65.

27. Cos O, Resina D, Ferrer P, Montesinos JL, Valero F. Heterologous production of Rhizopus oryzae lipase in Pichia pastoris using the alcohol oxidase and formaldehyde dehydrogenase promoters in batch and fed-batch cultures. Biochem Eng J. 2005;26:86-94.

28. Ross JS, Lawshé A, Koskie K, Johnson T, Caple MV, Zhang M. Rapid development and optimization of cell culture media. Taipei: BioPharm International; 2016. p. 21.

29. Weuster-Botz D. Experimental design for fermentation media development: statistical design or global random search? J Biosci Bioeng. 2000:90:473-83.

30. Mandenius C-F, Brundin A. Bioprocess optimization using design-ofexperiments methodology. Biotechnol Prog. 2008;24:1191-203.

31. Boer VM, de Winde JH, Pronk JT, Piper MD. The genome-wide transcriptional responses of Saccharomyces cerevisiae grown on glucose in aerobic chemostat cultures limited for carbon, nitrogen, phosphorus, or sulfur. J Biol Chem. 2003;278:3265-74.

32. Prielhofer R, Cartwright SP, Graf AB, Valli M, Bill RM, Mattanovich D, Gasser B. Pichia pastoris regulates its gene-specific response to different carbon sources at the transcriptional, rather than the translational, level. BMC Genom. 2015;16:167.

33. Russmayer H, Buchetics M, Gruber C, Valli M, Grillitsch K, Modarres G, Guerrasio R, Klavins K, Neubauer S, Drexler H, et al. Systems-level organization of yeast methylotrophic lifestyle. BMC Biol. 2015;13:80.
34. Rebnegger C, Graf AB, Valli M, Steiger MG, Gasser B, Maurer M, Mattanovich D. In Pichia pastoris, growth rate regulates protein synthesis and secretion, mating and stress response. Biotechnol J. 2014;9:511-25.

35. Zhang B, Li B, Chen D, Zong J, Sun F, Qu H, Liang C. Transcriptional regulation of aerobic metabolism in Pichia pastoris fermentation. PLOS ONE. 2016;11:e0161502.

36. Vanz AL, Lunsdorf H, Adnan A, Nimtz M, Gurramkonda C, Khanna N, Rinas U. Physiological response of Pichia pastoris GS115 to methanol-induced high level production of the Hepatitis B surface antigen: catabolic adaptation, stress responses, and autophagic processes. Microb Cell Fact. 2012;11:103.

37. Boer VM, Amini S, Botstein D. Influence of genotype and nutrition on survival and metabolism of starving yeast. Proc Natl Acad Sci USA. 2008;105:6930-5.

38. Prescott LM, Harley JP, Klein DA. Microbiology. Boston: McGraw-Hill Higher Education; 2002.

39. Gasser B, Sauer M, Maurer M, Stadlmayr G, Mattanovich D. Transcriptomics-based identification of novel factors enhancing heterologous protein secretion in yeasts. Appl Environ Microbiol. 2007;73:6499-507.

40. Conrad M, Schothorst J, Kankipati HN, Van Zeebroeck G, Rubio-Texeira M, Thevelein JM. Nutrient sensing and signaling in the yeast Saccharomyces cerevisiae. FEMS Microbiol Rev. 2014;38:254-99.

41. Hamasaki M, Noda T, Baba M, Ohsumi Y. Starvation triggers the delivery of the endoplasmic reticulum to the vacuole via autophagy in yeast. Traffic. 2005;6:56-65.

42. Krainer FW, Dietzsch C, Hajek T, Herwig C, Spadiut O, Glieder A. Recombinant protein expression in Pichia pastoris strains with an engineered methanol utilization pathway. Microb Cell Fact. 2012;11:22.

43. Yano T, Takigami E, Yurimoto H, Sakai Y. Yap1-regulated glutathione redox system curtails accumulation of formaldehyde and reactive oxygen species in methanol metabolism of Pichia pastoris. Eukaryot Cell. 2009;8:540-9.

44. Secco D, Wang C, Shou H, Whelan J. Phosphate homeostasis in the yeast Saccharomyces cerevisiae, the key role of the SPX domain-containing proteins. FEBS Lett. 2012;586:289-95.

45. Ramsay AM, Douglas $\sqcup$. Effects of phosphate limitation of growth on the cell-wall and lipid composition of Saccharomyces cerevisiae. J Gen Microbiol. 1979;110:185-91.

46. Saldanha AJ, Brauer MJ, Botstein D. Nutritional homeostasis in batch and steady-state culture of yeast. Mol Biol Cell. 2004;15:4089-104.

47. Markham E, Byrne WJ. Uptake, storage and utilization of phosphate by yeast III. the behaviour of phosphate-starved yeast. J Inst Brew. 1968;74:374-8.

48. Walker GM. Yeast physiology and biotechnology. Chichester: Wiley; 1998.

49. Thomas D, Surdin-Kerjan Y. Metabolism of sulfur amino acids in Saccharomyces cerevisiae. Microbiol Mol Biol Rev. 1997;61:503-32.

50. Kankipati HN, Rubio-Texeira M, Castermans D, Diallinas G, Thevelein JM. Sul 1 and Sul2 Sulfate transceptors signal to protein kinase a upon exit of sulfur starvation. J Biol Chem. 2015;290:10430-46.

51. Cherest H, Davidian J-C, Thomas D, Benes V, Ansorge W, Surdin-Kerjan Y. Molecular characterization of two high affinity sulfate transporters in Saccharomyces cerevisiae. Genetics. 1997;145:627-35.

52. Hogan DA, Auchtung TA, Hausinger RP. Cloning and characterization of a sulfonate/a-ketoglutarate dioxygenase from Saccharomyces cerevisiae. J Bacteriol. 1999;181:5876-9.

53. Zhang N, Merlotti C, Wu J, Ismail T, El-Moghazy AN, Khan SA, Butt A, Gardner DC, Sims PF, Oliver SG. Functional analysis of six novel ORFs on the left arm of chromosome XII of Saccharomyces cerevisiae reveals three of them responding to S-starvation. Yeast. 2001;18:325-34.

54. Isnard A-D, Thomas D, Surdin-Kerjan Y. The study of methionine uptake in Saccharomyces cerevisiae reveals a new family of amino acid permeases. J Mol Biol. 1996;262:473-84.

55. Sauer M, Branduardi P, Gasser B, Valli M, Maurer M, Porro D, Mattanovich D. Differential gene expression in recombinant Pichia pastoris analysed by heterologous DNA microarray hybridisation. Microb Cell Fact. 2004;3:17.

56. Carrillo E, Ben-Ari G, Wildenhain J, Tyers M, Grammentz D, Lee TA. Characterizing the roles of Met31 and Met32 in coordinating Met4-activated transcription in the absence of Met30. Mol Biol Cell. 2012;23:1928-42. 
57. Hébert A, Forquin-Gomez M-P, Roux A, Aubert J, Junot C, Heilier J-F, Landaud S, Bonnarme P, Beckerich J-M. New insights into sulfur metabolism in yeasts as revealed by studies of Yarrowia lipolytica. Appl Environ Microbiol. 2013;79:1200-11.

58. Blank HM, Gajjar S, Belyanin A, Polymenis M. Sulfur metabolism actively promotes initiation of cell division in yeast. PLOS ONE. 2009;4:e8018.

59. Pakula TM, Nygren H, Barth D, Heinonen M, Castillo S, Penttila M, Arvas M. Genome wide analysis of protein production load in Trichoderma reesei. Biotechnol Biofuels. 2016;9:132.

60. Magasanik B, Kaiser CA. Nitrogen regulation in Saccharomyces cerevisiae Gene. 2002;290:1-18.

61. Kurtzman C. Description of Komagataella phaffii sp. nov. and the transfer of Pichia pseudopastoris to the methylotrophic yeast genus Komagataella. Int J Syst Evol Microbiol. 2005;55:973-6.

62. Gutteridge A, Pir P, Castrillo Jl, Charles PD, Lilley KS, Oliver SG. Nutrient control of eukaryote cell growth: a systems biology study in yeast. BMC Biol. 2010;8:68.

63. Rumjantsev AM, Bondareva OV, Padkina MV, Sambuk EV. Effect of nitrogen source and inorganic phosphate concentration on methanol utilization and PEX genes expression in Pichia pastoris. Sci World J. 2014;2014:9.

64. Schröder M, Chang J, Kaufman R. The unfolded protein response represses nitrogen-starvation induced developmental differentiation in yeast. Genes Dev. 2000;14:2962-75.
65. Hofman-Bang J. Nitrogen catabolite repression in Saccharomyces cerevisiae. Mol Biotechnol. 1999;12:35-73.

66. Yuan W, Stromhaug PE, Dunn WA Jr. Glucose-induced autophagy of peroxisomes in Pichia pastoris requires a unique E1-like protein. Mol Biol Cell. 1999;10:1353-66.

67. Folk JE, Piez KA, Carroll WR, Gladner JA. Carboxy-peptidase B. 4. Purification and characterization of the porcine enzyme. J Biol Chem. 1960;235:2272-7.

68. Huber W, von Heydebreck A, Sultmann H, Poustka A, Vingron M. Variance stabilization applied to microarray data calibration and to the quantification of differential expression. Bioinformatics. 2002;18(Suppl 1):S96-104.

69. Reiner A, Yekutieli D, Benjamini Y. Identifying differentially expressed genes using false discovery rate controlling procedures. Bioinformatics. 2003;19:368-75.

70. Robinson MD, McCarthy DJ, Smyth GK. edgeR: a Bioconductor package for differential expression analysis of digital gene expression data. Bioinformatics. 2010;26:139-40.

71. Pfaffl MW. Quantification strategies in real-time PCR. In: Bustin SA, editor. A-Z of quantitative PCR. La Jolla: International University Line (IUL); 2004. p. 87-112.

\section{Submit your next manuscript to BioMed Central and we will help you at every step:}

- We accept pre-submission inquiries

- Our selector tool helps you to find the most relevant journal

- We provide round the clock customer support

- Convenient online submission

- Thorough peer review

- Inclusion in PubMed and all major indexing services

- Maximum visibility for your research

Submit your manuscript at www.biomedcentral.com/submit 